\title{
Highly Efficient Repair of the $\Delta$ F508 Mutation in Airway Stem Cells of Cystic Fibrosis Patients with Functional Rescue of the Differentiated Epithelia
}

Sriram Vaidyanathan ${ }^{\star 1}$, Ameen A. Salahudeen ${ }^{\star 2}$, Zachary M. Sellers ${ }^{\star 1}$, Dawn T. Bravo*3, Shannon S. Choi ${ }^{2}$, Arpit Batish², Wei Le ${ }^{3}$, Sean De La O², Milan P. Kaushik', Noah Galper $^{1}$, Ciaran M. Lee ${ }^{4}$, Gang Bao ${ }^{4}$, Eugene H. Chang ${ }^{5}$, Jeffrey J. Wine ${ }^{6}$, Carlos E. Milla $^{1}$, Tushar J. Desai ${ }^{+7}$, Jayakar V. Nayak ${ }^{+3}$, Calvin J. Kuo ${ }^{+2}$, Matthew H. Porteus ${ }^{+1}$

${ }^{*}$ Equal contributions as first authors.

+ Equal contributions as corresponding authors.

1. Department of Pediatrics, Stanford University, Stanford, CA 94304, USA

2. Department of Hematology, Stanford University, Stanford, CA 94305, USA

3. Department of Otolaryngology-Head and Neck Surgery, Stanford, CA 94305, USA

4. Department of Bioengineering, Rice University, Houston, TX 77030, USA

5. Department of Otolaryngology, University of Arizona - Tucson, Tucson, AZ 85724, USA

6. Department of Psychology, Stanford University, Stanford, CA 94305, USA

7. Department of Pulmonary and Critical Care Medicine, Stanford University, Stanford, CA 94305, USA

Correspondence should be addressed to:

Tushar J. Desai: tdesai@stanford.edu Jayakar V. Nayak: jnayak@stanford.edu Calvin J. Kuo: cjkuo@stanford.edu Matthew H. Porteus: mporteus@stanford.edu 


\section{Abstract}

Cystic fibrosis (CF) is a monogenic autosomal recessive disorder caused by mutations in the Cystic Fibrosis Transmembrane Conductance Regulator (CFTR) $\mathrm{Cl}^{-}$channel. CF results in multiorgan dysfunction and ultimately mortality from respiratory sequelae. Although pharmacologic approaches have demonstrated efficacy in reducing symptoms and respiratory decline, a curative treatment modality remains elusive. Gene therapy, a promising curative strategy, has been limited due to poor correction efficiencies both in vitro and in vivo. Here, we use Cas9 and adeno-associated virus 6 (AAV6) to correct the $\Delta$ F508 mutation (found in $~ 70 \%$ of CF alleles and $~ 90 \%$ of CF patients in North America) in upper airway basal stem cells (UABCs) obtained from CF and non-CF patients undergoing functional endoscopic sinus surgery (FESS). In UABCs from homozygous $(\Delta \mathrm{F} 508 / \Delta \mathrm{F} 508)$ and compound heterozygous ( $\Delta \mathrm{F} 508 /$ Other) $\mathrm{CF}$ patients, we achieved 28 $\pm 5 \%$ and $42 \pm 15 \%$ correction, respectively. In homozygous human bronchial epithelial cells (HBECs), we achieved $41 \pm 4 \%$ correction. Upon differentiation in air-liquid interface (ALI), cultures of corrected CF cells displayed partial restoration of CFTRinh-172 sensitive $\mathrm{Cl}^{-}$currents relative to non-CF controls: $31 \pm 5 \%$ in UABCs and $51 \pm 3 \%$ in HBECs (both from subjects homozygous for $\triangle \mathrm{F} 508$ CFTR). Finally, gene edited cells embedded successfully and retained expression of cytokeratin 5 (KRT5), a basal cell marker, on a FDA-approved porcine small intestinal submucosal (pSIS) membrane previously shown to improve re-mucosalization after FESS. In summary, we present an efficient, feederfree, selection-free and clinically compatible approach to generate cell-based therapies for CF from autologous airway stem cells. This approach represents a first step towards developing patient-specific autologous airway stem cell transplant as a curative treatment for CF.

\section{Introduction}

Cystic fibrosis (CF) is an autosomal recessive monogenic disease caused by mutations in the Cystic Fibrosis Transmembrane Conductance Regulator (CFTR) protein, a $\mathrm{Cl}^{-}$ channel. Although CF is a systemic disease that affects exocrine function in multiple organ systems, CF lung disease is the major cause of morbidity and mortality in CF patients. Over the past decade, small molecule CFTR correctors and potentiators have been developed, and represent a significant advancement in CF therapeutics (Van Goor et al., 2009, 2011). Although these small molecules improve lung function and reduce pulmonary exacerbations in patients, they are expensive, show variable therapeutic responses, have significant adverse effects (e.g. hepatotoxicity, dyspnea), must be administered daily (Wainwright et al., 2015) and necessitate lifelong treatment. As a result of these limitations, there is continued interest in developing genome editing strategies to correct CFTR mutations in stem cells for achieving durable restoration of native CFTR function.

Genome editing using zinc-finger nucleases or CRISPR/Cas9 has been attempted in intestinal stem cells and induced pluripotent stem cells (iPSCs), respectively (Crane et al., 2015; Firth et al., 2015; Schwank et al., 2013). Genome editing using nucleases involves the creation of a double-stranded break (DSB) which is then repaired using either 
the non-homologous end joining (NHEJ) or homologous recombination (HR) pathways. NHEJ results in insertions and deletions (INDELs) and cannot be used to precisely correct mutations. The HR pathway can be used to correct mutations but it has been challenging to achieve high levels of HR to correct CFTR mutations in primary stem cells. Previous studies focused on the $\Delta F 508$ mutation that affects $>70 \%$ of CFTR patients and employed selectable markers to enrich for cells corrected using the HR pathway. The efficiencies reported in these studies $(0.02 \%$ (Schwank et al., 2013) before selection and $16 \%$ after selection (Crane et al., 2015)) are useful to understand the pathophysiology of different mutations and may enable drug screening, but are too low for clinical utility. In addition to low correction frequencies, subsequent directed differentiation of iPSCs to produce a clinically relevant airway cell type remains a major challenge and the risk of teratoma formation from residual undifferentiated iPSCs in the population remains. In contrast, a highly efficient, selection-free, feeder-free, genome editing strategy in endogenous airway stem cells could facilitate the rapid development of durable cell therapies to treat CF airway disease.

We describe experiments using Cas9 and adeno-associated virus 6 (AAV6) to correct the $\Delta \mathrm{F} 508$ mutation using the HR pathway in ex-vivo expanded, human upper and lower airway cytokeratin 5+ (KRT5+) stem cells from the upper airway and bronchial epithelium, respectively. We pursued this ex-vivo correction strategy to overcome several obstacles associated with in vivo gene correction including successful vector delivery across the thick airway mucus barrier (Armstrong et al., 2014), and the immunogenicity to Cas9 that is highly prevalent in humans (Charlesworth et al., 2019; Wagner et al., 2018) and develops in animals after exposure to Cas9 in vivo (Wang et al., 2015a).

Recent studies have achieved $>50 \%$ allelic modification in hematopoietic stem cells, $\mathrm{T}$ cells, and embryonic stem cells using Cas9 with single guide RNA (sgRNA) modified with 2'-O-methyl 3'phosphorothioate (MS) in the 5' and 3' terminal nucleotides (MS-sgRNA) and correction templates delivered by AAV6 (Bak et al., 2018; Dever et al., 2016; Hendel et al., 2015; Martin et al., 2018). We modified and adapted this general strategy to airway stem cells. We present the following findings:

1. Correction of the $\Delta \mathrm{F} 508$ mutation in $28 \pm 5 \%$ and $42 \pm 15 \%$ alleles in KRT5+ basal stem cells derived from the upper airway epithelium of $\Delta \mathrm{F} 508$ homozygous and compound heterozygous patients, respectively. In addition, we achieved $41 \pm 4 \%$ correction in KRT5+ stem cells obtained from bronchial epithelia (HBECs) of $\Delta \mathrm{F} 508$ homozygous patients.

2. Corrected KRT5+ upper airway basal stem cells (UABCs) from homozygous CF patients differentiated in air-liquid interface showed $31 \pm 5 \%$ CFTR inh- 172 sensitive $\mathrm{Cl}^{-}$short-circuit currents relative to non-CF cultures subject to the same assay (Ma et al., 2002; Vu et al., 2017). By contrast, corrected KRT5+ HBECs showed $51 \pm$ $3 \%$ CFTRinh-172 sensitive $\mathrm{Cl}^{-}$short-circuit currents relative to non-CF HBEC cultures subjected to the same assay.

3. Gene edited KRT5+ UABCs were successfully embedded on a FDA-approved porcine small intestinal submucosal (pSIS) surgical matrix routinely used for 
epithelial repair during functional endoscopic sinus and skull base surgeries (FESS) (Nayak et al., 2018).

In addition to providing a highly efficient, clinically compatible approach for correcting the $\Delta$ F508 mutation, our experiments indicate that even mosaic correction of $50 \%$ or less of the stem cell population can achieve significant restoration of CFTR function within the in vitro differentiated epithelium. Combined with successfully embedding corrected cells on a FDA-compatible scaffold that is already in use for sinonasal repair, these experiments form the foundation for a strategy of transplanting genetically corrected autologous airway stem cells embedded in a matrix back into the airways of patients to potentially cure the respiratory complications of CF.

\section{Results:}

Isolation and culture of UABCs: Cas9-based gene editing utilizing the homologous recombination pathway to correct mutations has been shown to be improved under conditions that promote cell proliferation (Charlesworth et al., 2018). Therefore, we first optimized cell culture conditions to both increase proliferation of basal cells and improve their survival after electroporation (also called nucleofection).

We obtained sinonasal tissue from non-CF and CF patients undergoing FESS and performed pronase digestion and red blood cell lysis. On day zero, 2 - 22\% (mean \pm S.D. $=10 \pm 8 \%$ ) cells were found to express KRT5+, a marker for stem/progenitor cells in upper and lower airway epithelia (Figure S1A) (Bravo et al., 2013; Wang et al., 2015b). We initially cultured UABCs as 3-dimensional organoids without any feeder cells in Matrigel domes. Epidermal growth factor (EGF) along with the bone morphogenetic protein (BMP) antagonist Noggin were sufficient to promote organoid growth, alongside, the transforming growth factor- $\beta$ (TGF- $\beta$ ) inhibitor A83-01, and the Rho-kinase inhibitor Y-27632. Such UABC organoids submerged under media were KRT5+ (Fig. S1B-E). Under these feeder-free organoid conditions, KRT5+ UABCs were enriched after 5 days in culture from $10 \pm 8 \%$ to $72 \pm 18 \%$ (Figure S1A). Optimal cell density was empirically determined to be $\sim 10,000$ cells $/ \mathrm{cm}^{2}$ (Figure S1F).

Notably, human UABC could also be cultured and expanded as KRT5+ monolayers using the same EGF/Noggin media (EN media) used for culturing organoids (Fig. S2A). Using cells from the same donors as in Figure S1F, optimal cell density was empirically determined to be $\sim 10,000$ cells $/ \mathrm{cm}^{2}$ for cells cultured as monolayer and resulted in a similar fold-expansion of KRT5+ cells (Figure S2A). We attempted gene editing on UABCs cultured as organoids and cells cultured as monolayers using electroporation of a previously reported control homologous recombination (HR) template (or donor template) expressing green fluorescent protein (GFP) at the CCR5 locus (Hendel et al., 2015). Since HR was more efficient in basal cells cultured as monolayers (Fig. S2B), we used this approach in subsequent experiments with the EN media optimized from organoids. Optimal cell density was also tested for cells passaged as monolayers and was empirically determined to be $\sim 10,000$ cells $/ \mathrm{cm}^{2}$ at passage 1. (Figure S2C). Cell 
culture at $5 \% \mathrm{O}_{2}$ also improved cell proliferation of KRT5+ UABC monolayers compared to $21 \% \mathrm{O}_{2}$ (Figure S2D).

Insertion of Correction Sequence by Homologous Recombination in $\triangle F 508$ Locus: Several sgRNAs in the exon carrying the $\triangle F 508$ mutation (exon 11) were tested and the most efficient sgRNA (Figure 1A) was used for further experiments. This sgRNA is active even in non- $\triangle \mathrm{F} 508$ cells since the protospacer sequence is eight base pairs away from the $\Delta$ F508 mutation. AAV6 at a multiplicity of infection (MOI) of $10^{6}$ particles per cell was found to have the highest transduction among commonly used serotypes (Figure S3A-B). Silent mutations were introduced in the correction templates to both prevent re-cutting by Cas9 and to serve as a marker to quantify insertion in non- $\Delta \mathrm{F} 508$ cells. We tested the efficiency of two correction sequences carrying different silent mutations on HR (Figure S3C). In these experiments, the CFTR exon 11 locus was amplified using junction polymerase chain reaction (PCR) 4 days after editing, after which insertions and deletions (INDELs) and HR events were quantified using TIDER (Brinkman et al., 2018). We found that a correction sequence with 6 silent mutations surrounding the Cas 9 double-stranded break was more effective than one with 4 silent mutations (Figure S3C). Further experiments were thus performed with the codon diverged sequence carrying 6 silent mutations (Figure 1A).

Using the optimal template, our correction sequence was observed in $43 \pm 5 \%$ alleles (Figure 1B) and INDELs were observed in $38 \pm 2 \%$ of the alleles (Figure 1B), a ratio of $\mathrm{HR}$ :INDEL of $>1$ which is consistent with prior work that when optimal amounts of donor are delivered to dividing cells, high frequencies of HR-mediated editing are possible (Charlesworth et al., 2018; Hendel et al., 2014). On the day of extraction, $67 \pm 8 \%$ of edited cells were KRT5+ and Integrin Alpha-6+ (ITGA6+) which was similar to control (mock) cells, with $60 \pm 15 \%$ (Figure 1C-D). Thus, insertion of the correction sequence did not alter the phenotype of the targeted basal cells (Bravo et al., 2013; Wang et al., 2015b).

Off-target activity: Cas9 nucleases can tolerate mismatches between the sgRNA and genomic DNA sequences. This results in unintended off-target DSB depending on the number, position and distribution of mismatches (Hsu et al., 2013; Lin et al., 2014). Such off-target activity is undesirable as it can result in mutations in important genes (e.g., oncogenes). In-silico methods predicted over 50 possible off-target sites. The off-target activity of the MS-sgRNA was characterized at the top 47 predicted off-target sites (Table S1). Off-target activity above background levels $(0.1 \%)$ was observed in only one site. INDELs were observed in $0.17 \%$ of alleles in Chr11:111971753-111971775 (OT-41 in Table S1). This region corresponds to an intron of the gene coding for the protein DIXDC1. DIXDC1 is a regulator of Wnt signaling and has been shown to be active in cardiac and neural tissue but not in airway cells (Wang et al., 2006). The intronic target sequence is of no known functional significance and does not occur in the putative splice donor or acceptor sequences of the intron.

Correction of $\triangle F 508$ mutation in KRT5+ stem cells expanded from primary CF patient airway epithelia: We used the optimized protocol to correct the $\Delta \mathrm{F} 508$ mutation 
in both UABCs and HBECs from homozygous $(\triangle \mathrm{F} / \triangle \mathrm{F})$ patients and UABCs from compound heterozygous ( $\triangle F$ /other) patients. In UABCs and HBECs from homozygous patients, we observed allelic correction rates of $28 \pm 5 \%$ and $41 \pm 4 \%$ alleles, respectively. We observed $42 \pm 15 \%$ allelic correction in compound heterozygous UABC samples (Figure 2A). Gene-corrected airway cells cultured in air-liquid interface (ALI) using Transwells retained their ability to generate a pseudostratified epithelium with a basal layer of KRT5+ cells and a luminal layer of ciliated cells (acetylated $\alpha$-tubulin+) and mucin secreting cells (Muc5AC+) (Figure 2B-C). The fraction of edited cells did not change appreciably over the 28-35 days during which cells were cultured in $A L I$, suggesting equal contribution of corrected and uncorrected basal cells to reconstituting the epithelium (Figure 2D). Figure 2E shows a representative Western blot probing CFTR expression in non-CF, uncorrected and corrected CF samples after differentiation in ALI (CFTR Antibody 450). Mature CFTR expression was not observed in the uncorrected homozygous sample (lane 3 ) and was restored in cells corrected using the Cas9/AAV6 platform (lane 4). Mature CFTR expression in corrected cells was appreciable, although less than that seen in non-CF nasal cells (lane 2). These results indicate that gene edited basal cells can reconstitute an epithelium with restored CFTR protein expression in vitro.

Recovery of CFTR function in airway epithelial cells differentiated from genecorrected basal cells: To evaluate CFTR function, we differentiated UABCs and HBECs (corrected CF, uncorrected CF and non-CF) in air-liquid interface cultures and measured currents in short-circuited monolayers using Ussing chamber assays. Representative traces from non-CF and CF epithelial monolayers from UABCs are shown in Figure 2FG. Traces from epithelial monolayers derived from HBECs are shown in Figure S4. Consistent with expectations from Western blot results, corrected CF samples showed

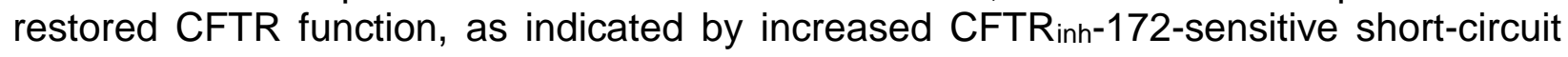
current (Figure 2G). Note that the forskolin-stimulated currents were small for both control and corrected monolayers. Because culture conditions can activate CFTR to various extents, the magnitude of responses to inhibition by CFTRinh-172 provide a better indication of CFTR function than does the magnitude of the forskolin response. CFTR inh- $^{-}$ 172-sensitive short-circuit currents in corrected samples were lower than corresponding short-circuit currents in non-CF samples. The CFTRinh-172-sensitive currents in edited UABCs and HBECs are presented as a percent of non-CF controls in Figure $2 \mathrm{H}$. Genotype information, percent alleles corrected and restoration of CFTRinh-172 shortcircuit currents relative to average non-CF currents for individual samples are presented in Table 1. The CFTRinh-172-sensitive currents from corrected UABCs $(n=4 \Delta F / \Delta F$ donors; $n=3 \Delta F /$ other; $n=3$ non-CF) and HBECs ( $n=3 \Delta F / \Delta F ; n=2$ non-CF) are plotted as a function of allelic correction in Figures $2 \mathrm{I}$ and $2 \mathrm{~J}$, respectively. UABC cultures from compound heterozygotes with higher editing efficiencies showed correspondingly greater restoration of CFTR function. HBEC samples from 3 donors had similar correction rates and showed similar CFTRinh-172-sensitive currents.

Corrected $\triangle F 508$ homozygous CF UABC cultures showed CFTRinh-172-sensitive shortcircuit currents of $13 \pm 3 \mu \mathrm{A} / \mathrm{cm}^{2}$ ( $31 \pm 5 \%$ relative to non-CF) which was significantly higher than currents of $0.78 \pm 0.04 \mu \mathrm{A} / \mathrm{cm}^{2}$ seen in uncorrected CF controls $(p<0.0001$, t-test). Corrected $\Delta \mathrm{F} 508$ compound heterozygous samples showed CFTRinh-172- 
sensitive short-circuit currents of $9 \pm 2 \mu \mathrm{A} / \mathrm{cm}^{2}$ (20 $\pm 5 \%$ relative to non-CF) which was significantly higher than uncorrected CF controls ( $p<0.0001$, t-test). Non-CF UABC

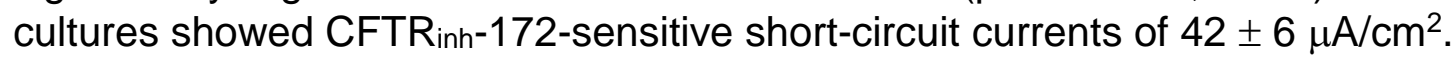

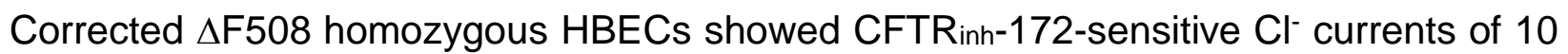
$\pm 1 \mu \mathrm{A} / \mathrm{cm}^{2}\left(51 \pm 3 \%\right.$ relative to non-CF) compared to $2 \pm 1 \mu \mathrm{A} / \mathrm{cm}^{2}$ seen in uncorrected $\triangle F 508$ homozygous HBECs $\left(p<0.0001\right.$, t-test) and $18 \pm 3 \mu \mathrm{A} / \mathrm{cm}^{2}$ seen in non-CF

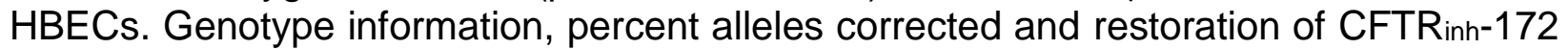
short-circuit currents relative to average non-CF currents for individual samples are presented in Table 1.

Gene Edited Basal Cells Can be Embedded in FDA-approved Porcine SIS membrane: As a path to transplanting ex vivo genetically corrected autologous cells into patients, we explored whether we could embed genetically edited airway cells on a pSIS membrane that is already in clinical use and FDA approved for several indications, including sinonasal repair (Nayak et al., 2018). We optimized the seeding density and culture conditions to obtain a monolayer of basal cells that retained expression of KRT5. We determined that the optimal plating density to achieve 50-70\% primary cell coverage in four days was 100,000 cells $/ \mathrm{cm}^{2}$ (Figure 3A). Hematoxylin and eosin (H\&E) staining of pSIS in cross-section showed cells embedded as a monolayer (Figure 3B). Cells seeded on pSIS membrane remained KRT5+ (Figure 3C subject 1, Figure S5 A-I Subjects 2-4). Manders' co-localization coefficients were calculated and the fraction of live (calcein green positive) cells also positive for KRT5 (M1) was determined to be $53 \pm 15 \%$ ( $n=4$ from 4 individual donors). The fraction of KRT5+ cells corresponded to the KRT5+ fraction measured on the day of seeding did not change appreciably after proliferating on the pSIS membrane (Figure S5J). Thus, the pSIS membrane is a suitable scaffold to optimize transplantation of corrected cells in animal models.

Discussion: The discovery of CF as a monogenic disease caused by CFTR mutations in 1989 prompted several attempts to use gene therapy for treatment (Griesenbach et al., 2015). These studies employed various viral and non-viral strategies but failed to show significant benefit (Griesenbach et al., 2015). The recent development of genome editing using Cas9 and other nucleases (e.g., zinc finger nucleases) has prompted a renewed effort to correct CF causing mutations. Although early studies achieved low levels of correction in intestinal stem cells and iPSCs (Crane et al., 2015; Firth et al., 2015; Schwank et al., 2013), correction of CFTR mutations at high efficiencies in therapeutically relevant primary airway stem cells has not previously been demonstrated.

In this study, we achieved correction of the $\Delta \mathrm{F} 508$ mutation in $\sim 40 \%$ of alleles in primary upper airway and bronchial basal stem cells obtained from CF patients. This level of correction is a 100-fold improvement over previous studies using CRISPR/Cas9 and is within the range necessary for clinically significant restoration of CFTR function. Significantly, our approach achieves this high level of correction without the use of any drug-based selection strategy (e.g., puromycin), a key feature that is relevant for clinical translation (Schwank et al., 2013). When cultured in air-liquid interfaces, corrected UABC and HBECs gave rise to differentiated epithelia containing ciliated and mucus producing 
cells. Different media and culture conditions have been reported for the culture of epithelial sheets in air-liquid interface (Gentzsch et al., 2017). To ensure that we measured true CFTR function, we tested two commonly used media conditions (Pneumacult ${ }^{\mathrm{TM}}$ ALI medium and ALI medium reported previously (Gentzsch et al., 2017)). Although there were differences in the response to forskolin, the response to CFTR inh172 was similar under both conditions in both non-CF and corrected CF cells (Figure S6). The data reported in Figure 2 are from cells cultured in Pneumacult ${ }^{T M}$. The differences in the forskolin response is likely due to the presence of factors that increase baseline CFTR stimulation (e.g. cholera toxin) but this is unknown since the composition of Pneumacult ${ }^{\mathrm{TM}}$ media is proprietary.

We observed restoration of CFTR function in both $\triangle F 508$ compound heterozygous as well as homozygous samples. However, since the sgRNA is located a few base pairs away from the $\triangle \mathrm{F} 508$ mutation site and is active in non-CF cells, half of the replaced alleles did not contain the $\Delta \mathrm{F} 508$ mutation. Therefore, as expected, a higher level of allelic correction ( 2-fold higher) is required in compound heterozygous samples for equivalent restoration of CFTR function. Previous studies have attempted to ascertain the minimal level of correction necessary to restore normal $\mathrm{Cl}^{-}$transport by co-culturing non-CF or corrected CF cells and CF cells in ALI. These reports indicate that $10-50 \%$ normal cells are sufficient to restore non-CF level $\mathrm{Cl}^{-}$transport in $\triangle \mathrm{F} 508$ homozygotes (Johnson et al., 1992; Shah et al., 2016). Another study used a lentivirus based strategy to overexpress CFTR under the control of an RSV promoter in pig epithelia (Cooney et al., 2016). They reported low genomic integration (<1 copy per 10 cells) but observed high levels of CFTR function. The minimal level of gene correction in the endogenous CFTR locus that can restore CFTR function to non-CF levels has not been previously reported. We detected as much as 2 -fold difference in CFTR function in technical replicates from the same CF donor despite the same level of correction in cells from the same individuals (Table 1, Figure $2 \mathrm{H}$ ). On average, $30-40 \%$ allelic correction restored CFTR function to $50 \%$ of non-CF levels in bronchial cells. However, one bronchial sample with $40 \%$ allelic correction showed $99 \%$ CFTR function relative to non-CF controls. Average CFTR function is approximately $60 \%$ higher in corrected HBECs (50\% of non-CF levels) than UABCs (30\% of non-CF levels). However, since the UABCs and HBECs were not from the same donors, it is unclear if the differences are due to underlying biology of these related but still distinct cells or due to differences in the genetic backgrounds of the individuals.

CFTR function has been reported to vary logarithmically in organ outputs measured in vivo (e.g. sweat chloride) and has been shown to be rate-limiting at low levels of CFTR expression (Char et al., 2014). Thus, even augmentation to a low level of CFTR function may provide significant clinical benefit. For example, patients homozygous for the $\mathrm{R} 117 \mathrm{H}$ mutation experience infertility and mildly increased sweat chloride but are completely free of any respiratory or pancreatic symptoms (De Nooijer et al., 2011). Significantly, R117H and other class IV mutations are associated with significantly lower mortality compared to class II mutations such as $\Delta$ F508 (McKone et al., 2003). Patch clamp and apical conductance measurements on cells expressing exogenous R117H-CFTR showed as little as $15 \% \mathrm{Cl}^{-}$conductance relative to cells expressing wild-type CFTR (Sheppard et 
al., 1993). By way of contrast, Char et al. estimated $<2 \%$ CFTR function relative to WT levels in patients with $\mathrm{R} 117 \mathrm{H}$ mutations (Char et al., 2014). Thus, the $20-50 \%$ function relative to WT in CFTR function we found in our studies would be predicted to provide a meaningful clinical benefit to patients if achieved in vivo. This benefit may also be expected to be durable, suggested by our findings that targeting basal stem cells for gene correction does not impair their ability to contribute to differentiated airway epithelial cells.

Achieving correction of CFTR mutations in vivo, either by transplanting corrected cells or editing in vivo, remains a hurdle for gene therapy. Transplantation of airway stem cells into the lower airways have been reported in animal models but further optimization is necessary for clinical use (Rosen et al., 2015). We focused our experiments on upper airway basal cells since the ease of access to upper airway tissue may help clinical translation by providing readily accessible airway stem cells and by enabling surveillance of the sites after transplantation. Moreover, sinuses of CF patients have been shown to act as a reservoir for drug resistant pathogens that cause chronic lung infections (Hansen et al., 2012). Thus, chronic rhinosinusitis and recurrent infectious disease of the upper airways are unmet medical needs that affect CF patients. Chronic rhinosinusitis and recurrent infections are not ameliorated by lung transplantation and AAV mediated gene therapy in the maxillary sinus was unsuccessful (Wagner et al., 2002). The surface area of one maxillary sinus has been estimated to be $\sim 13 \mathrm{~cm}^{2}$ (Oliveria et al., 2014). Given that $10^{5}$ cells $/ \mathrm{cm}^{2}$ on the pSIS membrane represents an optimal cell density, we estimate that 1.3 million corrected cells will be sufficient to completely cover the surface of one maxillary sinus even without any lateral outgrowth of gene-corrected basal cells following implantation. This cell yield is entirely achievable using our current approach, and transplantation with in vivo analysis will be the focus of our future studies.

Conclusion: Our study shows that a platform consisting of Cas9, MS-sgRNA and AAV6 can be used to correct the $\Delta \mathrm{F} 508$ mutation in primary airway stem/progenitor cells obtained from CF patients. This selection-free strategy achieves clinically significant restoration of CFTR function in differentiated epithelial sheets derived from corrected stem cells. The study paves the way for future experiments to optimize the transplantation of corrected UABCs into the upper airway to treat CF sinus disease. Successful optimization of stem cell transplantation into the sinuses may then enable further investigations on the use of cell therapies to treat CF lung disease.

\section{Experimental Methods}

EN media: ADMEM/F12 supplemented with B27 supplement, Nicotinamide (10 mM), human EGF (50 ng/mL), human Noggin (100 ng/mL), A83-01 (500 nM), N-acetylcysteine (1 $\mathrm{mM})$ and HEPES (1 $\mathrm{mM})$

Cell Culture: Upper airway tissue obtained from endoscopic surgery was cut into small pieces (1-2 $\left.\mathrm{mm}^{2}\right)$. Tissue pieces were washed with $10 \mathrm{ml}$ sterile, PBS w/2X antibiotic/antimycotic (Penicillin, Streptomycin, Amphotericin B, Gibco \# 15240062) on ice and digested with pronase $\left(1.5 \mathrm{mg} / \mathrm{mL}\right.$, Sigma \#P5147) for $2 \mathrm{~h}$ at $37^{\circ} \mathrm{C}$ or at $4{ }^{\circ} \mathrm{C}$ overnight. Digestion was stopped using 10\% FBS. Digested tissue was filtered through 
cell strainers (BD Falcon \# 352350) into a sterile $50 \mathrm{ml}$ conical tube. The mixture was centrifuged at $600 x \mathrm{x}$ for 3 minutes at room temperature. RBC lysis was then performed using RBC lysis buffer (eBioscience ${ }^{\mathrm{TM}}$ ) as per manufacturer's instructions. After RBC lysis, cells were suspended in $1 \mathrm{~mL}$ EN media and counted. A small sample was fixed using $2 \%$ paraformaldehyde and permeabilized using Tris-buffered saline with $0.1 \%$ Tween 20. Cells were stained for cytokeratin 5 (KRT5, Abcam, ab 193895). An isotype control (Abcam, ab 199093) was used to control for non-specific staining. KRT5+ cells were plated at a density of 10,000 cells per $\mathrm{cm}^{2}$ as monolayers in tissue culture plates coated with $5 \%$ Matrigel. Cells were incubated at $37{ }^{\circ} \mathrm{C}$ in $5 \% \mathrm{O}_{2}$ and $5 \% \mathrm{CO}_{2}$ in EN media with $10 \mu \mathrm{M}$ ROCK inhibitor (Y-27632, Santa Cruz, sc-281642A). Organoids were grown as $40 \mu$ Matrigel domes submerged under identical medium at initial seeding density of KRT5+20,000 cells/dome. Cells obtained from CF patients were grown in EN media supplemented with additional antimicrobials for two days (Fluconazole $-2 \mu \mathrm{g} / \mathrm{mL}$, Amphotericin B $1.25 \mu \mathrm{g} / \mathrm{mL}$, Imipenem - $12.5 \mu \mathrm{g} / \mathrm{mL}$, Ciprofloxacin - $40 \mu \mathrm{g} / \mathrm{mL}$, Azithromycin - $50 \mu \mathrm{g} / \mathrm{mL}$, Meropenem - $50 \mu \mathrm{g} / \mathrm{mL}$ ). The concentration of antimicrobials was decreased 50\% after 2-3 days and then withdrawn after editing (day 5-6).

Gene Editing: Cells were cultured in EN media with $10 \mu \mathrm{M}$ ROCK inhibitor (Y-27632, Santa Cruz, sc-281642A). The presence of ROCK inhibitor for at least $24 \mathrm{~h}$ was critical for cell survival after electroporation. Media was replaced on day 3 and day 4 after plating from tissue. Gene correction was performed 5 days after plating. Cells were detached using TrypLE Express Enzyme (Gibco ${ }^{\mathrm{TM}}$ 12605010). Cells were resuspended in OPTIMEM (Gibco ${ }^{\mathrm{TM}} 31985062$ ) at a density of 5 million cells $/ \mathrm{mL}$. Other electroporation buffers were also tested but the best results were obtained with OPTI-MEM. A similar observation has been reported in intestinal organoids (Fujii et al., 2015). Electroporation (Nucleofection) was performed using Lonza 4D 16-well Nucleocuvette ${ }^{\mathrm{TM}}$ Strips (Lonza, V4XP-3032). $6 \mu \mathrm{g}$ of Cas9 (Integrated DNA Technologies, IA, Cat: 1074182) and $3.2 \mu \mathrm{g}$ of MS-sgRNA (Trilink Biotechnologies, CA) (molar ratio = 1:2.5) were complexed at room temperature for 10 minutes. 100,000 cells $(20 \mu \mathrm{L}$ of OPTI-MEM with 5 million cells $/ \mathrm{mL})$ was added to Cas9/MS-sgRNA mixture used per well and transferred to the strip. Cells were electroporated using the program CA-137. $80 \mu \mathrm{L}$ of OPTI-MEM was added to each well after electroporation. Cells were transferred to a 12 well plate coated with $5 \%$ Matrigel (density $=20,000$ cells $/ \mathrm{cm}^{2}$ ) and $400 \mu \mathrm{L}$ of EN media with $10 \mu \mathrm{M}$ ROCK inhibitor was added. AAV carrying the correction template was added immediately after electroporation to maximize transduction (Bak et al., 2018; Charlesworth et al., 2018). Multiplicity of Infection (MOI) of $10^{6}$ particles per cell (as determined by qPCR) was optimal. AAV titers can also be determined by droplet digital PCR (ddPCR) but the output results in titers are 10-fold lower for the same sample when compared to qPCR. If AAV titer is measured using ddPCR, the appropriate $\mathrm{MOI}$ would be $10^{5}$ particles per cell. Media was replaced $48 \mathrm{~h}$ after electroporation. Gene correction levels were measured at least 4 days after electroporation. 
Measuring Gene Correction: 4 days (or more) after gene correction, genomic DNA was extracted from cells using Quick Extract (Lucigen, QE09050) as per manufacturer's instructions. The $\Delta \mathrm{F} 508$ locus was amplified using the primers:

Forward: CCTTCTACTCAGTTTTAGTC Reverse: TGGGTAGTGTGAAGGGTTCAT

The PCR product was sanger sequenced (primer: AGGCAAGTGAATCCTGAGCG) and the percent of corrected alleles was determined using TIDER.

Measuring off-target activity: Primary UABCs from non-CF patients were electroporated with Cas9 and sgRNA without the HR template. gDNA was extracted 4-5 days after RNP delivery. Potential off-target sites were identified using the bioinformatic tool COSMID (Cradick et al., 2014) allowing for 3 mismatches within the 19 PAM proximal bases. Predicted off-target loci were initially enriched by locus specific PCR followed by a second round of PCR to introduce adaptor and index sequences for the Illumina MiSeq platform. All amplicons were normalized, pooled and quantified using a Qubit (ThermoFisher Scientific) and were sequenced using a MiSeq Illumina using 2 x 250bp paired end reads. INDELs at potential off-target sites were quantified as previously described (Lee et al., 2016).

Air-Liquid Interface Culture of Corrected UABCs and HBECs: Gene corrected cells were plated 4-10 days after editing. 30,000 to 60,000 cells per well were plated in 6.5 $\mathrm{mm}$ Transwell plates with $0.4 \mu \mathrm{m}$ pore polyester membrane insert. EN media was used to expand cells for 1-2 weeks. Once cells were confluent in Transwell inserts and stopped translocating fluid, media in the bottom compartment was replaced with Pneumacult ALI media. For comparison, a small batch of cells were also cultured in media obtained from the University of North Carolina (UNC media)(Gentzsch et al., 2017). The need for an additional coating of plates with collagen IV was also tested.

Immunoblot: Immunoblotting methods were used to compare CFTR protein expression pre/post-correction. Calu-3 cells, non-CF nasal cells, and patient-derived $\Delta \mathrm{F} 508$ homozygous pre/post-correction were plated and cultured according to the above methods. Lysis was performed by incubating cells for 15 minutes in ice-cold RIPA buffer supplemented with EDTA-free protease inhibitor. Lysates were gathered and rotated at $4^{\circ} \mathrm{C}$ for $30 \mathrm{~min}$, then spun at $10,000 \times \mathrm{g}$ at $4^{\circ} \mathrm{C}$ for 10 minutes to pellet insoluble genomic material. The supernatant was collected and mixed with $2 x$ Laemmli sample buffer containing $100 \mathrm{mM}$ DTT and subsequently heated at $37^{\circ} \mathrm{C}$ for $30 \mathrm{~min}$. Approximately 5 $\mu \mathrm{g}$ of total protein was loaded for Calu-3 lane, and approximately $14 \mu \mathrm{g}$ of total protein was loaded for non-CF nasal and $\triangle \mathrm{F} 508$ cell lines and fractionated by SDS-PAGE, then transferred onto PVDF membrane. Blocking was performed with $5 \%$ nonfat milk in TBST (10 mM Tris, pH 8.0, $150 \mathrm{mM} \mathrm{NaCl}, 0.5 \%$ Tween 20) for $60 \mathrm{~min}$. The membrane was probed with antibodies against CFTR (Ab450, 1:1000), and $\beta$-actin $(1: 10,000)$. Membranes were washed and incubated with a 1:10,000 dilution of horseradish peroxidase-conjugated anti-mouse for $1 \mathrm{~h}$, then developed by SuperSignal ${ }^{\mathrm{TM}}$ West Femto Maximum Sensitivity Substrate (Thermo Fisher Scientific, 34095). 
Ussing Chamber Functional Assays: Ussing chamber measurements were performed 3-5 weeks after cells had stopped translocating fluid as described before. For $\mathrm{Cl}^{-}$secretion experiments with UABCs, and HBECs, solutions were as following in $\mathrm{mM}$ : Mucosal: NaGluconate 120, $\mathrm{NaHCO}_{3} \quad 25, \mathrm{KH}_{2} \mathrm{PO}_{4} \quad 3.3, \mathrm{~K}_{2} \mathrm{HPO}_{4} \quad 0.8, \mathrm{Ca}$ (Gluconate) ${ }^{2} \quad 4$, $\mathrm{Mg}$ (Gluconate) $^{2}$ 1.2, Mannitol 10; Serosal: $\mathrm{NaCl} 120, \mathrm{NaHCO}_{3}, 25, \mathrm{KH}_{2} \mathrm{PO}_{4} 3.3, \mathrm{~K}_{2} \mathrm{HPO}_{4}$ $0.8, \mathrm{CaCl}_{2} 1.2, \mathrm{MgCl}_{2} 1.2$, Glucose 10 . The concentration of ion channel activators and inhibitors were as follows:

Amiloride - $10 \mu \mathrm{M}$ - Mucosal

Forskolin - $10 \mu \mathrm{M}$ - Bilateral

VX-770 - $10 \mu \mathrm{M}-$ Mucosal

CFTRinh-172 - $20 \mu \mathrm{M}$ - Mucosal

UTP $-100 \mu \mathrm{M}-$ Mucosal

Embedding cells on pSIS membrane: pSIS membranes (Biodesign ${ }_{\circledast}$ Sinonasal Repair Graft; COOK Medical, Bloomington, IN) were placed in 8 well confocal chambers. UABCs were seeded 4-8 days after electroporation. Four days after seeding, cells were incubated with calcein green for 15 min and the excess washed away. Cells were imaged using a dissection scope to identify densities that provided optimal coverage. pSIS membranes with cells were fixed with $4 \%$ paraformaldehyde, permeabilized with TBS-T $(0.1 \%$ Tween 20) and stained for KRT5 (ab193895) and imaged using Leica SP8 confocal microscope. 


\section{Key resources:}

\begin{tabular}{|c|c|c|}
\hline Reagent or Resource & Source & Identifier \\
\hline \multicolumn{3}{|c|}{ Antibodies } \\
\hline $\begin{array}{l}\text { Anti-Cytokeratin } 5 \text { antibody } \\
\text { [EP1601Y] (Alexa Fluor® 647) }\end{array}$ & Abcam & ab193895 \\
\hline $\begin{array}{l}\text { Rabbit IgG, monoclonal } \\
\text { [EPR25A] - Isotype Control } \\
\text { (Alexa Fluor® 647) }\end{array}$ & Abcam & ab199093 \\
\hline $\begin{array}{c}\text { Alexa Fluor® } 488 \text { anti- } \\
\text { human/mouse CD49f Antibody }\end{array}$ & Biolegend & 313608 \\
\hline & Biological Samples & \\
\hline $\begin{array}{c}\text { Upper airway basal cells } \\
\text { (UABCs) }\end{array}$ & $\begin{array}{l}\text { Stanford University } \\
\text { University of Arizona }\end{array}$ & $\mathrm{N} / \mathrm{A}$ \\
\hline $\begin{array}{l}\text { Bronchial epithelial cells } \\
\text { (HBECs) }\end{array}$ & Lonza, McGill University & $\mathrm{N} / \mathrm{A}$ \\
\hline \multicolumn{3}{|c|}{ Reagents } \\
\hline $\begin{array}{l}\text { Adeno-associated Virus } \\
\text { Serotype } 6 \text { with } \Delta \text { F508 } \\
\text { correction template }\end{array}$ & Vigene Inc & Custom order \\
\hline $\begin{array}{c}\text { Adeno-associated Virus } \\
\text { Serotypes } 1,2,5,6,7,8,9, \text { DJ } \\
\text { with UBC-GFP }\end{array}$ & Vigene Inc & Custom Order \\
\hline $\begin{array}{c}\text { Alt-R® S.p. Cas9 Nuclease } \\
\text { 3NLS, } 500 \mu \mathrm{g}\end{array}$ & Integrated DNA technologies & 1074182 \\
\hline Primers & Integrated DNA technologies & $\mathrm{N} / \mathrm{A}$ \\
\hline MS-sgRNA & Trilink Biotechnologies & $0-5200$ \\
\hline Y-27632 dihydrochloride & Santacruz Biotechnology & sc-281642A \\
\hline HEPES & Gibco & $15630-080$ \\
\hline GlutaMAX-1 (100x) & Gibco & $35050-061$ \\
\hline NIC (Nicotinamide) & Sigma & N0636 \\
\hline B-27 supplement (50x) & Gibco & $125870-01$ \\
\hline A83-01 & Torcis & 2939 \\
\hline Human EGF & R\&D & 236-EG-01M \\
\hline Human Noggin & R\&D & 6057-NG/CF \\
\hline admem F-12 & Invitrogen & $12634-028$ \\
\hline Biodesign $^{\text {TM }}$ Sinonasal Graft & Cook Medical & G35950 \\
\hline $\begin{array}{c}\text { CellTrace }^{\mathrm{TM}} \text { Calcein Green, } \\
\text { AM }\end{array}$ & Invitrogen & C34852 \\
\hline Anti-CFTR antibody 450 & University of North Carolina & $\mathrm{N} / \mathrm{A}$ \\
\hline Pneumacult ${ }^{\mathrm{TM}}$ ALI media & Stem Cell Technologies & \#05001 \\
\hline Pneumacult ${ }^{\mathrm{TM}}$ Ex-Plus & Stem Cell Technologies & 05040 \\
\hline
\end{tabular}




\section{Acknowledgements}

We thank Dr. Scott Randell (University of North Carolina) for guidance on Ussing chamber assays and training on air-liquid interface cultures. We thank Dr. Jeffrey Beekman and Dr. Gimano Amatngalim for their guidance on Ussing chamber assays. The work was funded by grants from the California Institute of Regenerative Medicine (DISC209637), Stanford-SPARK MCHRI and the Cancer Prevention and Research Institute of Texas (RR14008 and RP170721). 


\section{Figure 1}

A

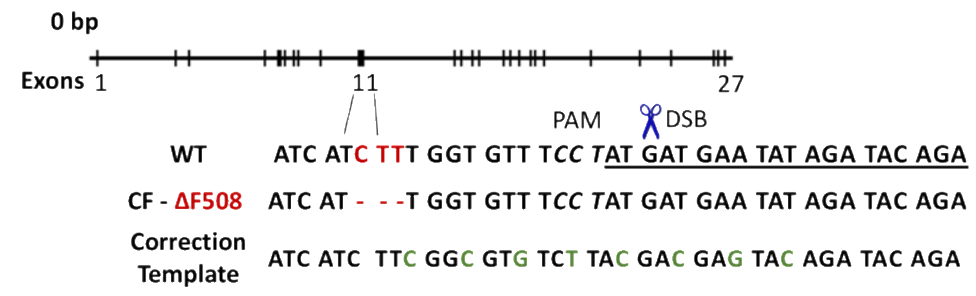

C

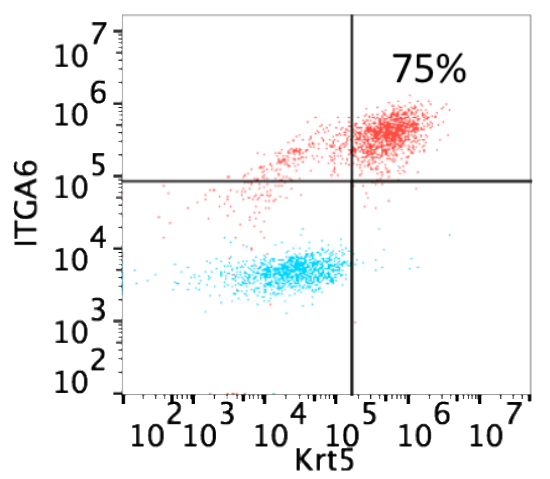

B

$\Delta$ F508 Replacement in Non-CF UABCs

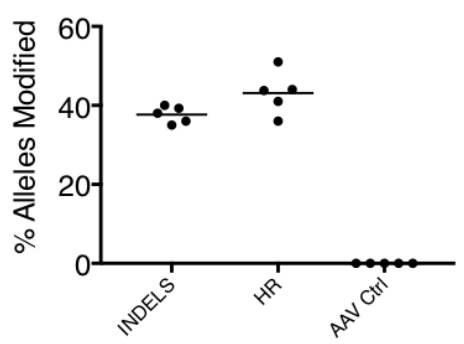

D

Krt5 ${ }^{+} \mathrm{ITGA}^{+}$cells in Edited Population Isotype Control Stained cells

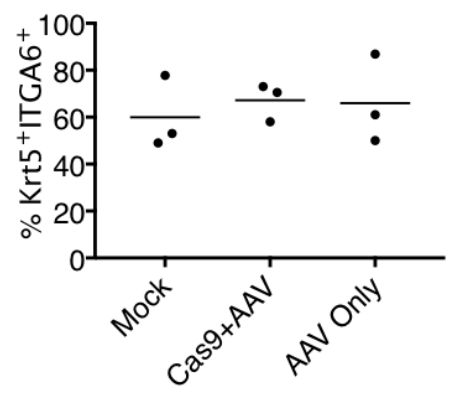

Figure 1: (A) Schematic describing the Cas9/AAV mediated strategy to correct $\Delta F 508$. The underlined segment represents the sequence complementary to sgRNA used. The PAM (protospacer adjacent motif) is indicated in italics for the wild-type (WT) sequence. Silent mutations introduced in the correction template to prevent re-cutting by Cas 9 are colored in green. (B) The region around exon 11 was amplified using IN-OUT PCR to quantify INDELS and HR using TIDER. INDELs were observed in $38 \pm 2 \%$ alleles and HR was observed in $43 \pm 5 \%$ alleles. Controls treated with only AAV did not show any INDELs or HR. (C) On day 4 after editing, the UABCs were stained for KRT5 and Integrin alpha 6 (ITGA6). A representative FACS plot shows that $75 \%$ of edited cells were KRT5+ITGA6+ (D) In trials on three different donors, the KRT5+ITGA6+ population was similar between control and edited UABCs. 
bioRxiv preprint doi: https://doi.org/10.1101/561183; this version posted February 26,2019 . The copyright holder for this preprint (which was not certified by peer review) is the author/funder, who has granted bioRxiv a license to display the preprint in perpetuity. It is made available under aCC-BY-NC-ND 4.0 International license.

\section{Figure 2}

A

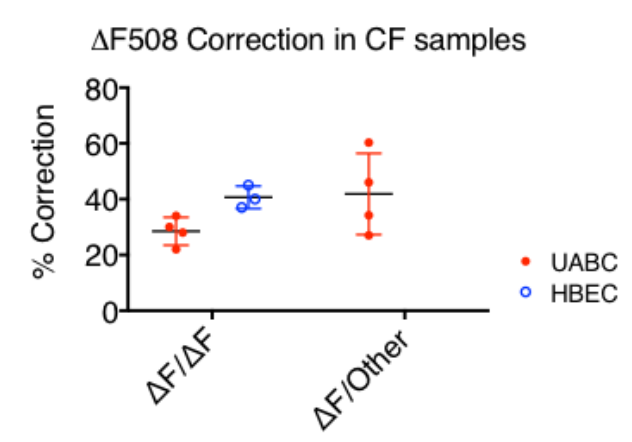

C

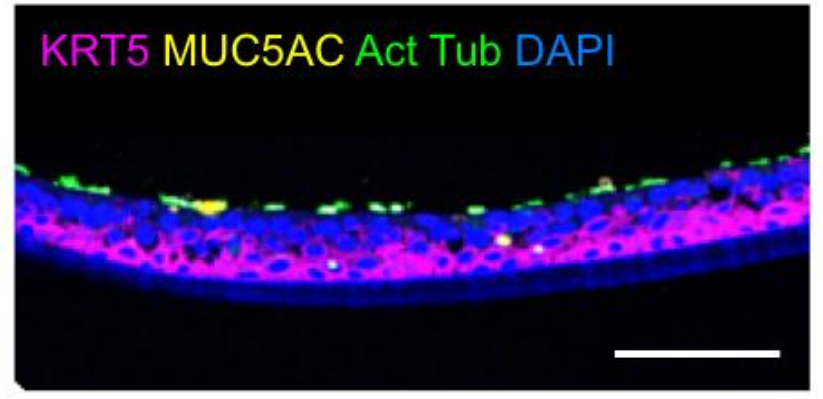

E

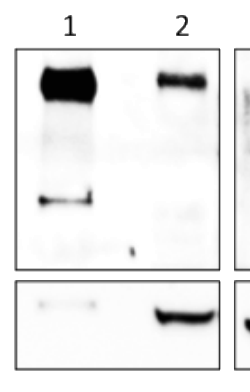

1. Calu-3

2. WT Nasal Cells
B

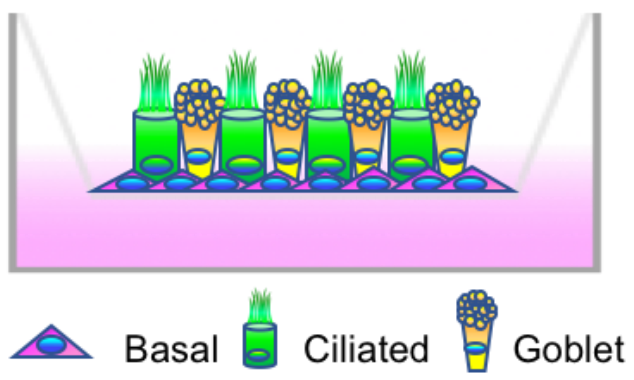

D

\section{Allelic Correction Frequencies in Epithelial Sheets}

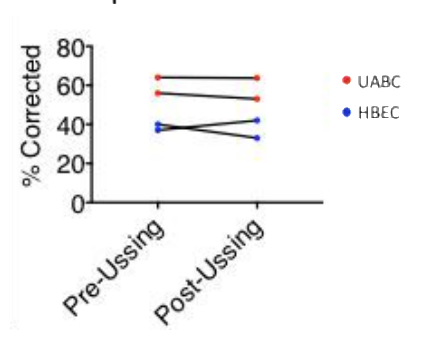

$\mathrm{F}$

Non-CF

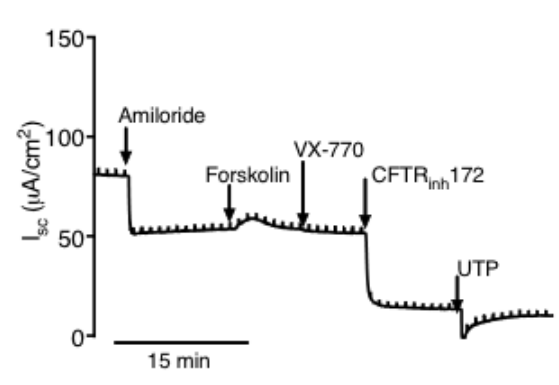


G

$\Delta \mathrm{F} / \triangle \mathrm{F} U A B C$

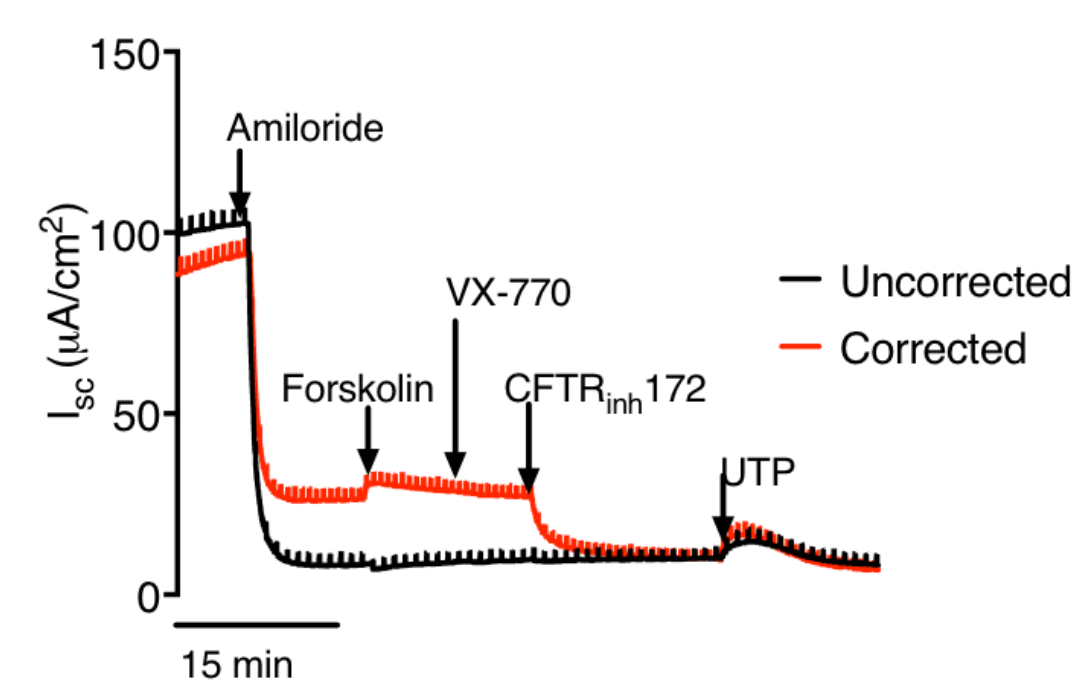

$\mathrm{H}$

\section{CFTR $_{\text {inh }}-172$ Response in Edited UABCs and HBECs}

Relative to Non-CF Controls

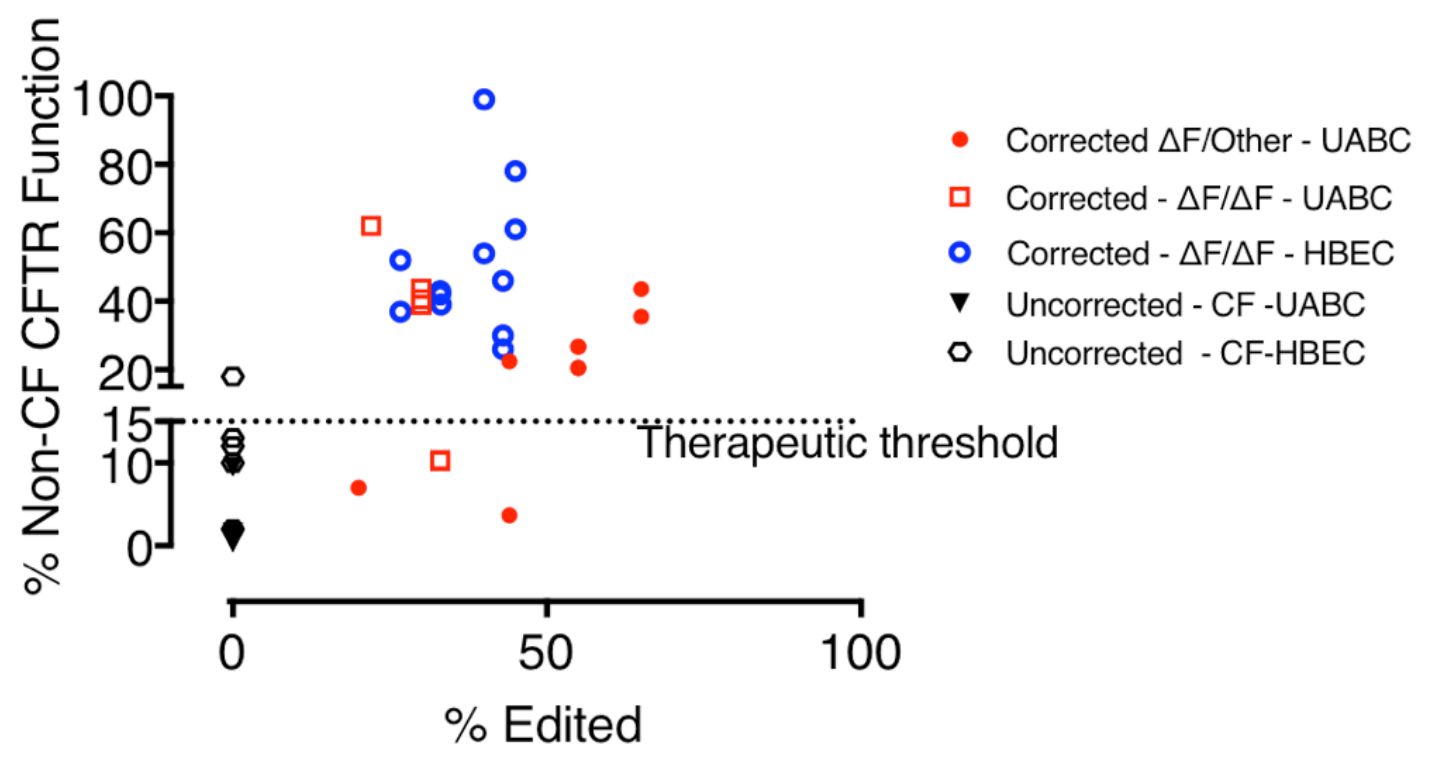


Restoration of CFTR inh -172 Response in UABCs

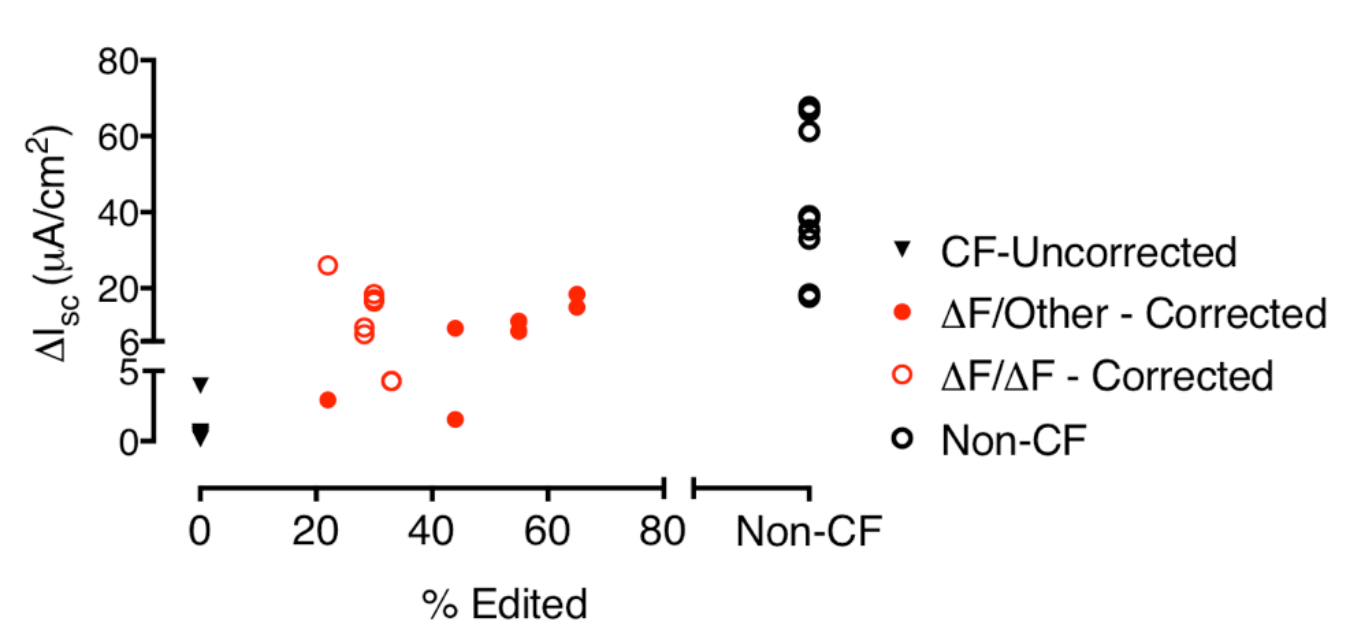

\section{Restoration of $\mathrm{CFTR}_{\text {inh }}$-172 Response in HBECs}

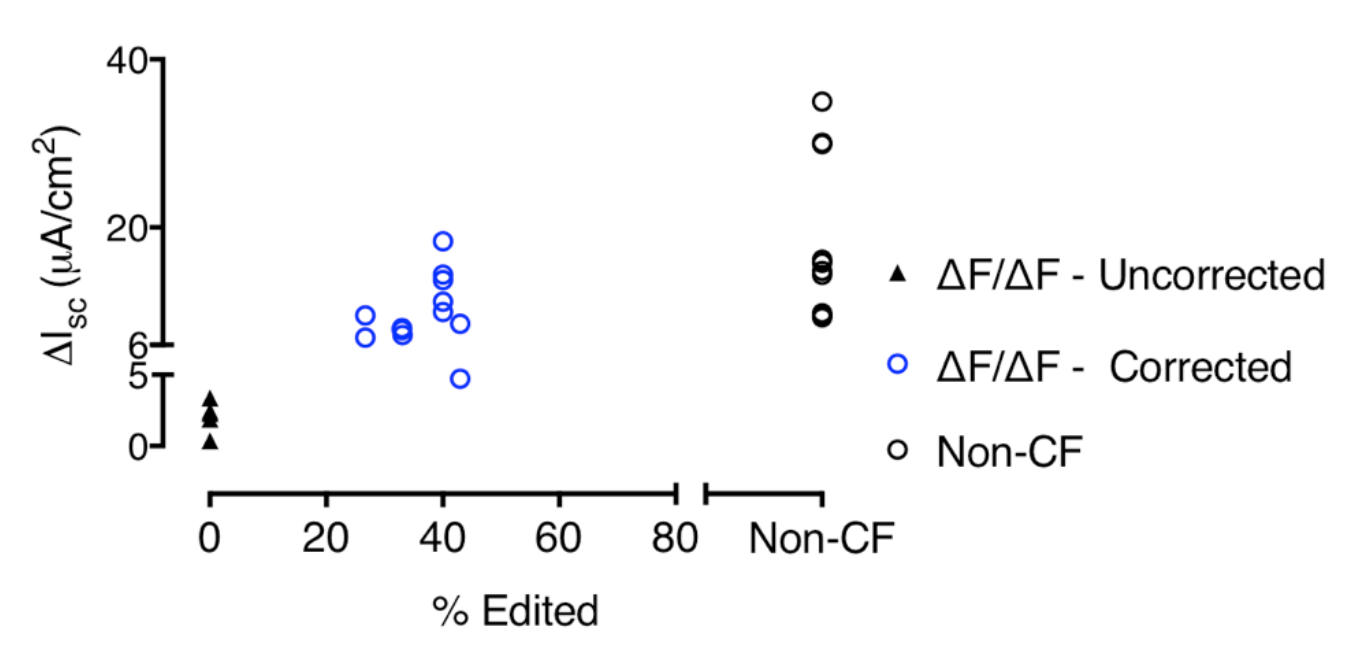

Figure 2: (A) Summary of percent alleles exhibiting HR in CF patient samples $(\Delta F / \Delta F-$ homozygous and $\Delta F$ /other - Compound heterozygous) (B) Illustration of ideal ALI culture platform, with KRT5+ basal cells giving rise to overlying ciliated and goblet differentiated cell types (C) Edited CF cells cultured on ALI differentiate into a sheet with basal cells (KRT5+), ciliated cells ( $\alpha$-tubulin+) and mucus producing cells (Muc5AC+). (D) Allelic correction rates in edited cells were assessed at the time of plating on ALI and at the end of the Ussing assay 28-35 days later. Allelic correction rates as measured by TIDER did not change appreciably before and after culturing in ALI for Ussing assays, suggesting equal contribution of corrected and uncorrected basal cells to reconstituting the epithelium. (E) Western blot probing CFTR expression. Calu-3 cells were used as a positive control for mature CFTR (lane 1). Despite a lower amount of total protein being 
loaded in the gel, Calu- 3 cells exhibited very high levels of CFTR expression. Calu- 3 cells also showed lower expression of $\beta$-actin. Non-CF nasal cells (lane 2) showed a clear band corresponding to the higher molecular-weight mature CFTR (Band A). Mature CFTR expression was absent in non-edited $\Delta \mathrm{F} 508$ homozygous $(\Delta F / \Delta F)$ cells (lane 3 ) but a faint, lower molecular-weight band corresponding to immature CFTR was present (CFTR Band $\mathrm{B}) . \Delta \mathrm{F} 508$ homozygous $(\Delta \mathrm{F} / \Delta \mathrm{F})$ cells after correction showed a restored mature CFTR band (lane 4) while also retaining a portion of the immature CFTR band. $\beta$-actin was used as a loading control. (F) Representative traces obtained from epithelial monolayers by Ussing chamber analysis in non-CF patients (G) Representative traces obtained from epithelial monolayers by Ussing chamber analysis in uncorrected and corrected $\Delta$ F508 homozygous samples. (H) CFTRinh-172 sensitive short-circuit currents observed in corrected CF samples as a percent of non-CF controls (UABCs: $\triangle F / \Delta F: n=$ 4 donors, $\Delta F /$ other: $\mathrm{n}=3$ donors. HBECs: $\Delta \mathrm{F} / \Delta \mathrm{F}: \mathrm{n}=3$ donors). Studies in patients with milder mutations have suggested that even $15 \%$ CFTR function relative to non-CF subjects would be therapeutically beneficial (Char et al., 2014; Sheppard et al., 1993). (I) CFTRinh-172-sensitive short-circuit currents observed in non-CF, uncorrected and corrected CF UABC samples as a function of editing $(\Delta \mathrm{F} / \Delta \mathrm{F}: \mathrm{n}=4$ donors, $\Delta \mathrm{F} /$ other: $\mathrm{n}=$ 3 donors and non-CF: $n=3$ donors) (J) CFTRinh-172-sensitive short-circuit currents observed in non-CF, uncorrected and corrected CF HBECs as a function of editing ( $\mathrm{n}=$ 3 donors, non-CF: $\mathrm{n}=2$ donors) 


\section{Figure 3}

A
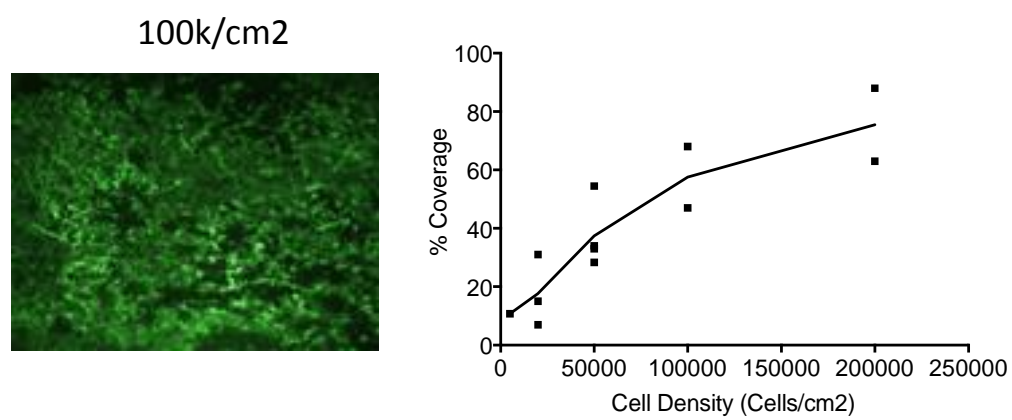

B

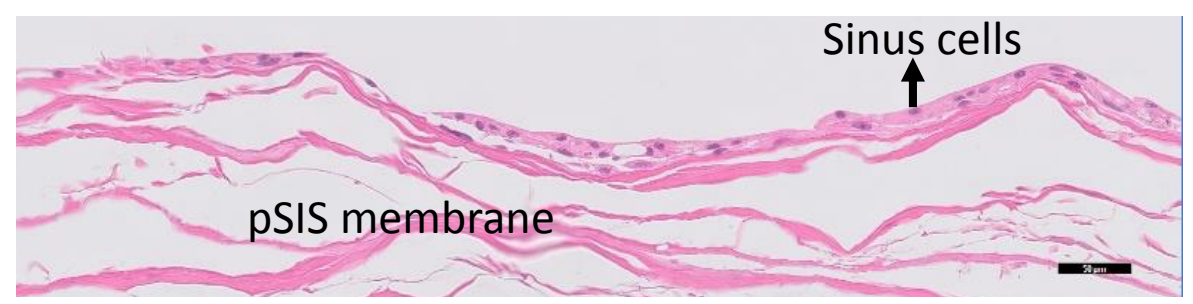

C
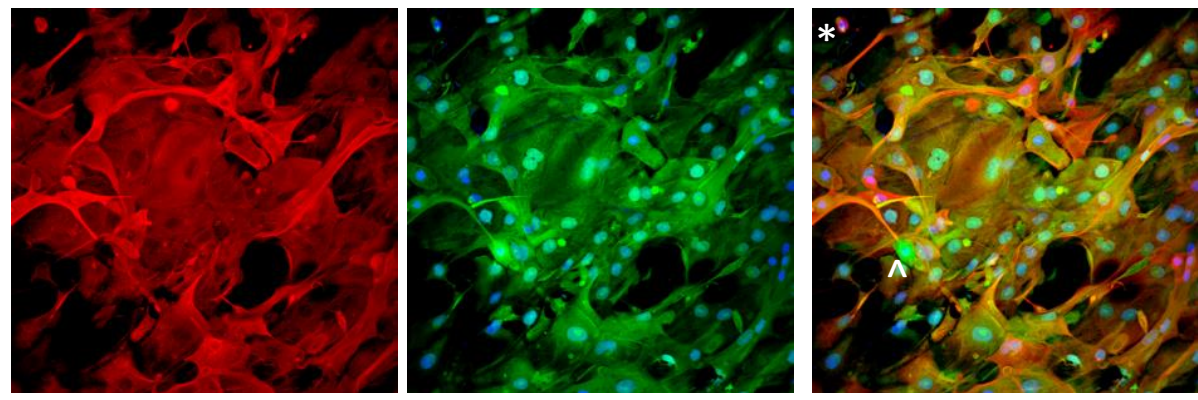

Krt5

Calcein Green

Hoescht

Figure 3: (A) Edited UABC cells plated on pSIS membranes at a density of $10^{5} \mathrm{cells} / \mathrm{cm}^{2}$ resulted in $50-70 \%$ confluence in four days (B) H\&E staining shows a monolayer of cells on pSIS membranes (scale $=50 \mu \mathrm{m}$ ) (C) Sheets fixed on day 4 after embedding on pSIS membrane were KRT5+. Calcein green indicates live cells and KRT5+ cells are stained red. A few cells are positive for calcein green but not KRT5 $\left({ }^{\wedge}\right)$. Some non-viable cells were still KRT5+ $\left(^{*}\right)$. Manders' coefficients were calculated. The fraction of calcein green positive cells also positive for KRT5 was determined to be $78 \%$ for sample presented here (average $=53 \pm 15 \%$ for $n=4$ biological replicates). 
Table 1: Summary of Percent Allelic Correction of ( $\triangle \mathrm{F} 508)$ in CF UABC and HBEC Samples and Relative CFTR Function with Respect to Non-CF Controls

\begin{tabular}{|c|c|c|c|c|c|c|c|}
\hline Patient & Genotype & $\begin{array}{l}\text { Percent } \\
\text { Editing }\end{array}$ & $\begin{array}{c}\text { Raw } \\
\text { Inhibitable } \\
\text { CF current } \\
(\mu \mathrm{A})\end{array}$ & $\begin{array}{c}\text { Percent } \\
\text { Non-CF } \\
\text { inhibitable } \\
\text { Current }\end{array}$ & $\begin{array}{l}\text { Cell } \\
\text { Type }\end{array}$ & Sex & Age \\
\hline \multicolumn{8}{|c|}{ Non-CF Inhibitable Current UABC (Mean \pm S.D. $)=42 \pm 6$} \\
\hline Patient 1 & $\Delta \mathrm{F} /$ Other & 22 & -2.93 & 7 & UABC & Male & 22 \\
\hline Patient 2 & $\Delta \mathrm{F} /$ Other & 44 & -1.55 & 5 & UABC & Female & 26 \\
\hline Patient 2 & $\Delta \mathrm{F} /$ Other & 44 & -9.5 & 22 & UABC & Female & 26 \\
\hline Patient 3 & $\Delta \mathrm{F} /$ Other & 66 & -18.41 & 45 & UABC & Male & 44 \\
\hline Patient 3 & $\Delta \mathrm{F} /$ Other & 66 & -15 & 35 & UABC & Male & 44 \\
\hline Patient 3 & $\Delta \mathrm{F} /$ Other & 54 & -8.67 & 21 & UABC & Male & 44 \\
\hline Patient 3 & $\Delta \mathrm{F} /$ Other & 54 & -11.27 & 27 & UABC & Male & 44 \\
\hline Patient 3 & $\Delta \mathrm{F} /$ Other & 54 & -11.32 & 27 & UABC & Male & 44 \\
\hline Patient 3 & $\Delta \mathrm{F} /$ Other & 54 & -8.71 & 21 & UABC & Male & 44 \\
\hline Patient 4 & $\Delta \mathrm{F} / \Delta \mathrm{F}$ & 30 & -17.16 & 41 & UABC & Male & 19 \\
\hline Patient 4 & $\Delta \mathrm{F} / \Delta \mathrm{F}$ & 30 & -16.46 & 39 & UABC & Male & 19 \\
\hline Patient 4 & $\Delta \mathrm{F} / \Delta \mathrm{F}$ & 30 & -18.45 & 44 & UABC & Male & 19 \\
\hline Patient 5 & $\Delta \mathrm{F} / \Delta \mathrm{F}$ & 33 & -4.27 & 10 & UABC & Unknown & Unknown \\
\hline Patient 5 & $\Delta \mathrm{F} / \Delta \mathrm{F}$ & 33 & -4.29 & 10 & UABC & Unknown & Unknown \\
\hline Patient 6 & $\Delta \mathrm{F} / \Delta \mathrm{F}$ & 22 & -26.04 & 76 & UABC & Male & 32 \\
\hline Patient 7 & $\Delta \mathrm{F} / \Delta \mathrm{F}$ & 28 & -9.7 & 28 & UABC & Unknown & Unknown \\
\hline Patient 7 & $\Delta \mathrm{F} / \Delta \mathrm{F}$ & 28 & -7.87 & 22 & UABC & Unknown & Unknown \\
\hline \multicolumn{8}{|c|}{ Non-CF Inhibitable Current HBEC (Mean \pm S.D. $)=18 \pm 3$} \\
\hline Patient 8 & $\Delta \mathrm{F} / \Delta \mathrm{F}$ & 33 & -7.75 & 42 & HBEC & Male & 25 \\
\hline Patient 8 & $\Delta \mathrm{F} / \Delta \mathrm{F}$ & 26.7 & -6.87 & 37 & HBEC & Male & 25 \\
\hline Patient 8 & $\Delta \mathrm{F} / \Delta \mathrm{F}$ & 33.1 & -7.19 & 39 & HBEC & Male & 25 \\
\hline Patient 8 & $\Delta \mathrm{F} / \Delta \mathrm{F}$ & 43 & -5.51 & 30 & HBEC & Male & 25 \\
\hline Patient 8 & $\Delta \mathrm{F} / \Delta \mathrm{F}$ & 43 & -4.73 & 26 & HBEC & Male & 25 \\
\hline Patient 8 & $\Delta \mathrm{F} / \Delta \mathrm{F}$ & 43 & -8.52 & 46 & HBEC & Male & 25 \\
\hline Patient 8 & $\Delta \mathrm{F} / \Delta \mathrm{F}$ & 26.7 & -9.52 & 52 & HBEC & Male & 25 \\
\hline Patient 8 & $\Delta \mathrm{F} / \Delta \mathrm{F}$ & 33 & -8 & 43 & HBEC & Male & 25 \\
\hline Patient 9 & $\Delta \mathrm{F} / \Delta \mathrm{F}$ & 40 & -9.91 & 54 & HBEC & Male & 32 \\
\hline Patient 9 & $\Delta \mathrm{F} / \Delta \mathrm{F}$ & 40 & -18.36 & 99 & HBEC & Male & 32 \\
\hline Patient 10 & $\Delta \mathrm{F} / \Delta \mathrm{F}$ & 45 & -13.71 & 61 & HBEC & Male & 44 \\
\hline Patient 10 & $\Delta \mathrm{F} / \Delta \mathrm{F}$ & 45 & -11.17 & 78 & HBEC & Male & 44 \\
\hline
\end{tabular}




\section{Figure S1}

A

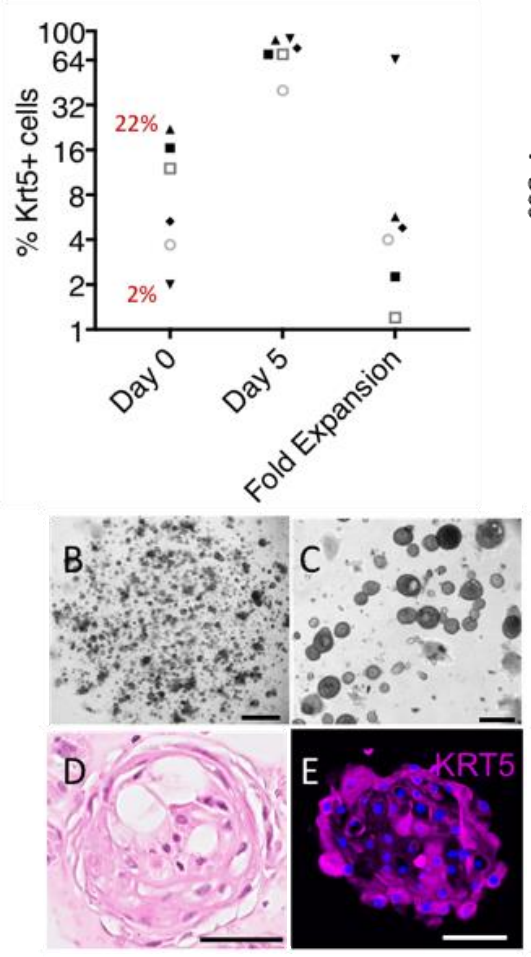

Day 0

(Representative FACS plot) (Representative FACS plot)
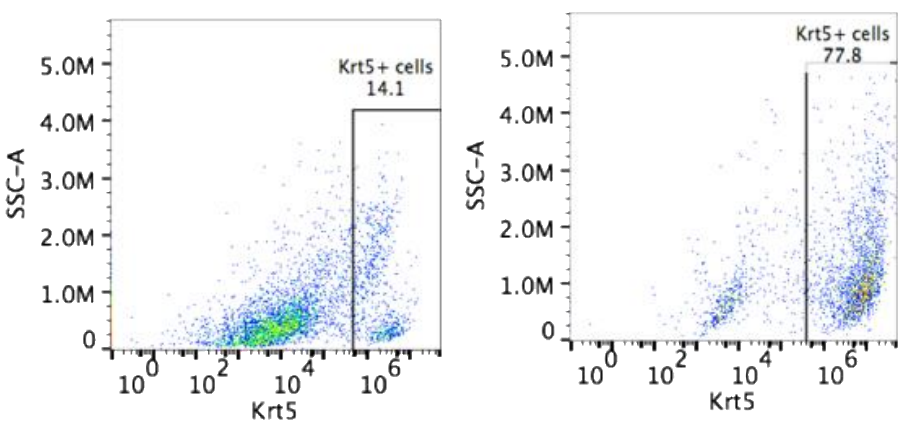

$\mathrm{F}$

Passage 0 - Organoids

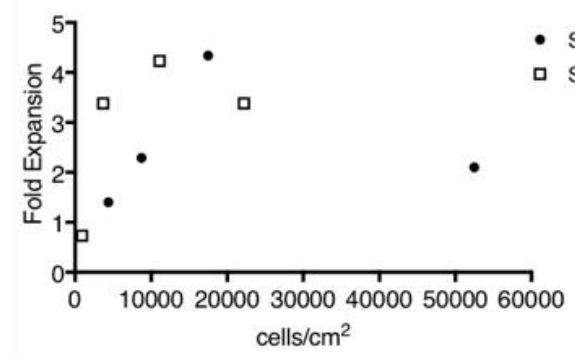

Figure S1. Characterization of human UABC organoids. (A) Percent KRT5+ cells on day $0(2-22 \%$, average $\pm \mathrm{SD}=10 \pm 8 \%)$, day $5(40-90 \%$, average $\pm \mathrm{SD}=72 \pm 18 \%)$ and fold expansion observed in 6 subjects (2 - 64\%). Representative FACS plots of UABC organoids with KRT5+ gating on day 0 versus day 5. (B-E) Primary human UABCs were cultured as organoids in Matrigel domes in EN medium $(A$, scale $=1 \mathrm{~mm}$ and $B$, scale $=$ $0.2 \mathrm{~mm})$. Organoids were assessed by $\mathrm{H} \& \mathrm{E}$ staining $(\mathrm{C}$, scale $=50 \mu \mathrm{m})$. Organoids were positive for KRT5 immunofluorescence (D, day 5 , scale $=50 \mu \mathrm{m}$ ) at culture day 5 . (F) Optimal organoid proliferation was observed at cells densities between 10,000-20,000 cells $/ \mathrm{cm}^{2}$ at passage 0 . 


\section{Figure S2}

A

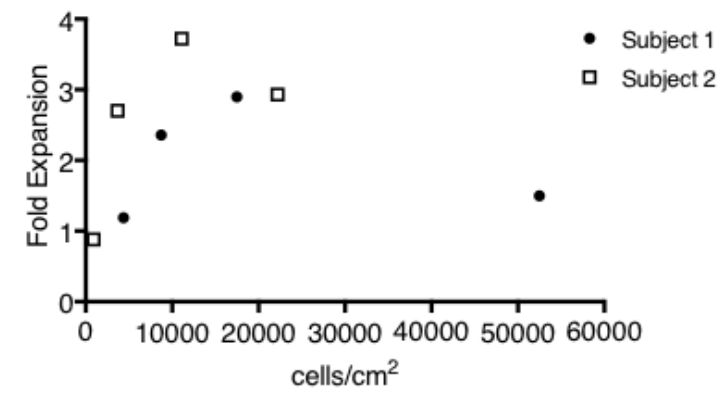

C

Passage 1

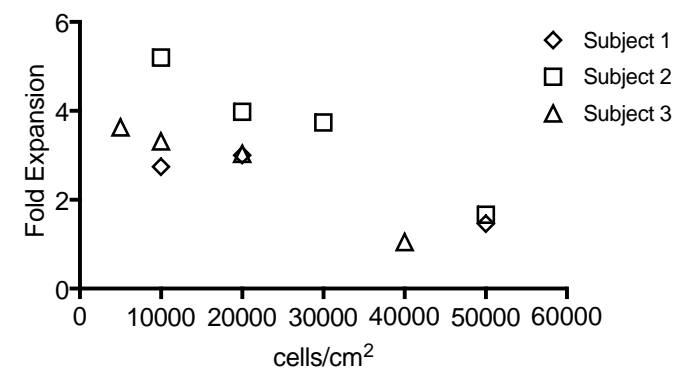

B

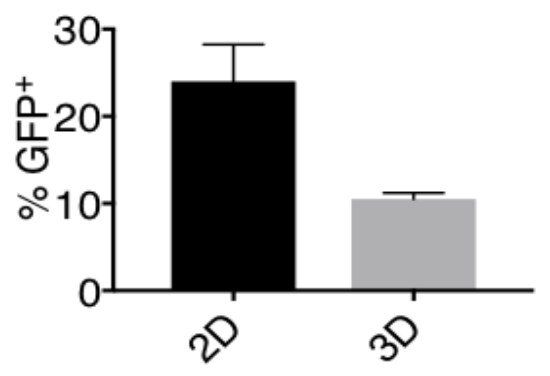

D $5 \% \mathrm{O}_{2} / 21 \% \mathrm{O}_{2}$ Expansion

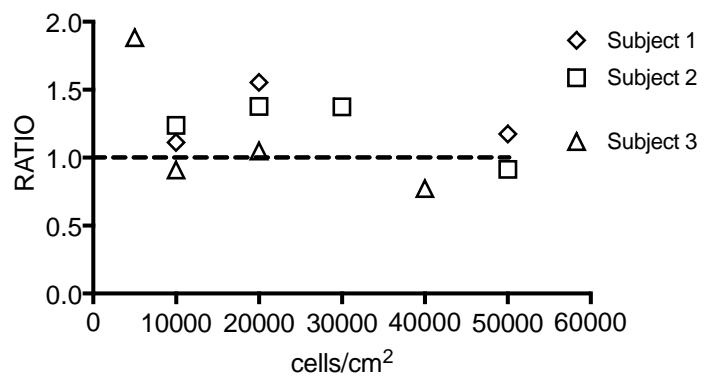

Figure S2. Improved gene editing in UABC monolayers versus 3D organoids. (A) Primary human UABCs were cultured as monolayers in tissue culture treated plates coated with 5\% Matrigel in EN medium. Optimal organoid proliferation was observed at cells densities between 10,000-20,000 cells $/ \mathrm{cm}^{2}$ at passage 0 . (B) Cells cultured both as monolayers and organoids were edited to express SFFV/GFP at the CCR5 locus using a previously reported construct (Hendel et al., 2015). Editing efficiencies were higher for cells cultured as monolayers ( $N=3, p=0.02$ by paired t-test) (C) Optimal cell density was also assessed in passaged cells and cell densities between 10,000-20,000 cells $/ \mathrm{cm}^{2}$ were optimal at passage 1. (D) Culturing UABC monolayers in $5 \% \mathrm{O}_{2}$ improved proliferation of cells from 2 out of 3 subjects (subjects 1 and 2). 


\section{Figure S3}

A

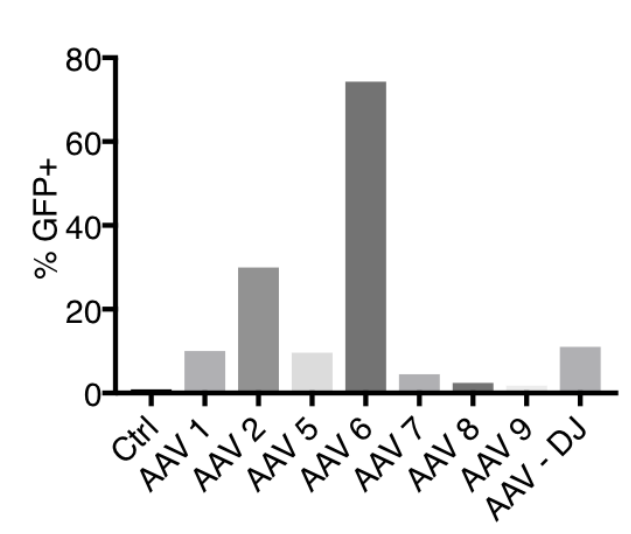

C

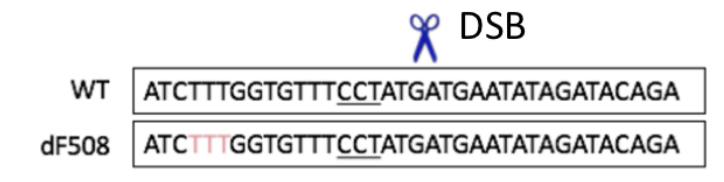

Correction TTcGGcGTgTCLTAcGAcGAgTACAGATACAG

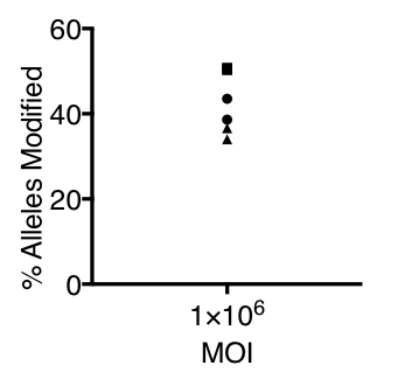

B
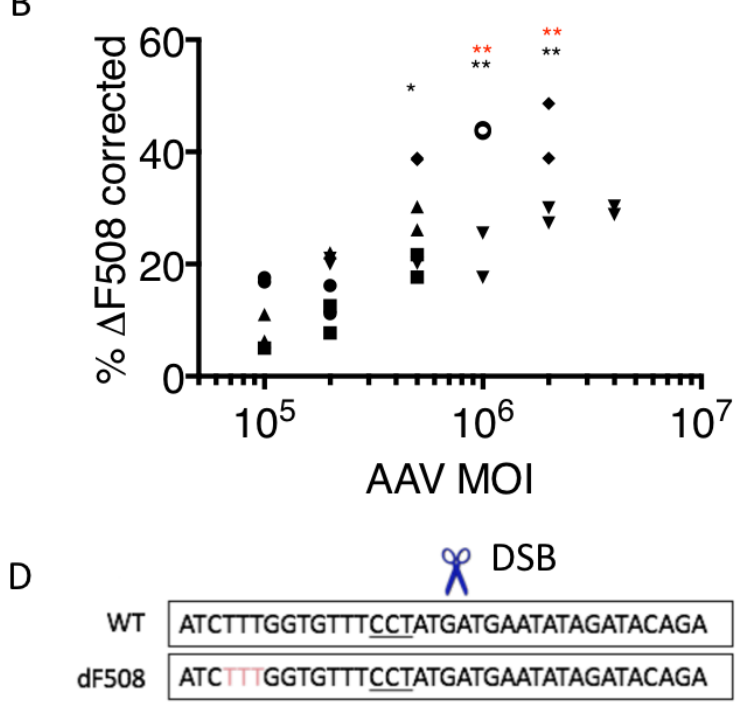

Correction TTcGGcGTgTCtTAcGATGAATATAGATACAG

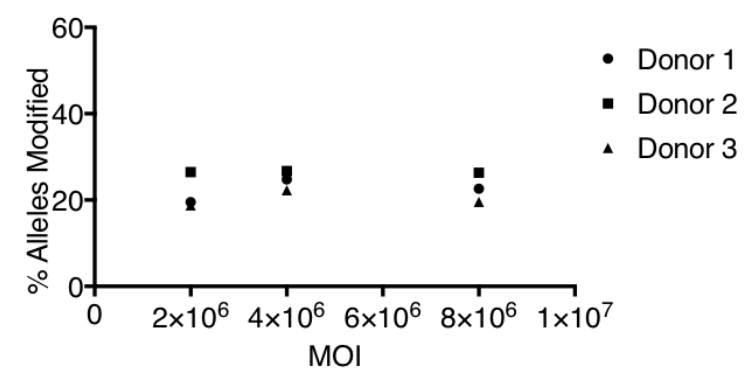

Figure S3: (A) AAV6 showed the best transduction in upper airway basal cells (UABCs). UABCs were transduced within 5 min after electroporation (B) In UABCs obtained from non-CF patients, MOls of $10^{6}$ and $2 \times 10^{6} \mathrm{M}$ vector genomes ( $\mathrm{vg}$ )/cell showed significantly higher editing compared to MOls $<2 \times 10^{5} \mathrm{vg} / \mathrm{cell}$. Different symbols represent cells from a different donor. (C-D) Two different correction templates with varying amounts of silent mutations (lower case letters) around the DSB site (scissors) were tested. PAM sequence is underlined. Templates with silent mutations on both sides of the DSB site (C) resulted in higher HR than templates containing mutations on one side (D). 


\section{Figure S4}

A Uncorrected $\triangle \mathrm{F} / \triangle \mathrm{F} \mathrm{HBECS}$

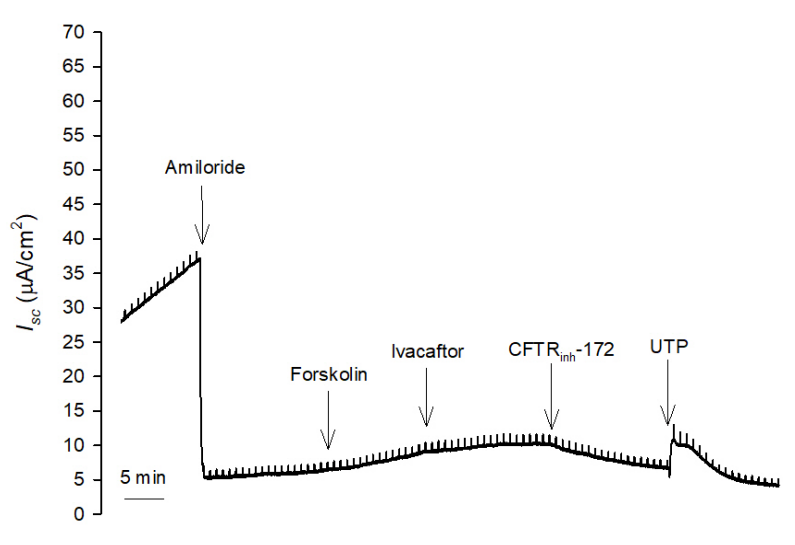

B Corrected $\Delta \mathrm{F} / \triangle \mathrm{F} \mathrm{HBECS}$

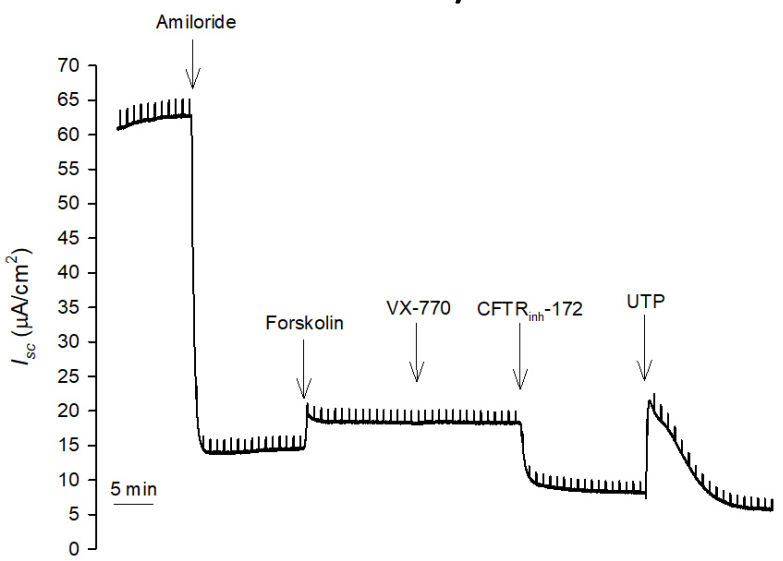

Figure S4: (A) Representative traces obtained from epithelial monolayers derived from $\Delta \mathrm{F} 508$ homozygous $(\Delta \mathrm{F} / \Delta \mathrm{F})$ CF HBECs; (B) Correction of $\Delta \mathrm{F} 508$ mutation in $30 \%$ of alleles resulted in a restoration of CFTR function 


\section{Figure S5}
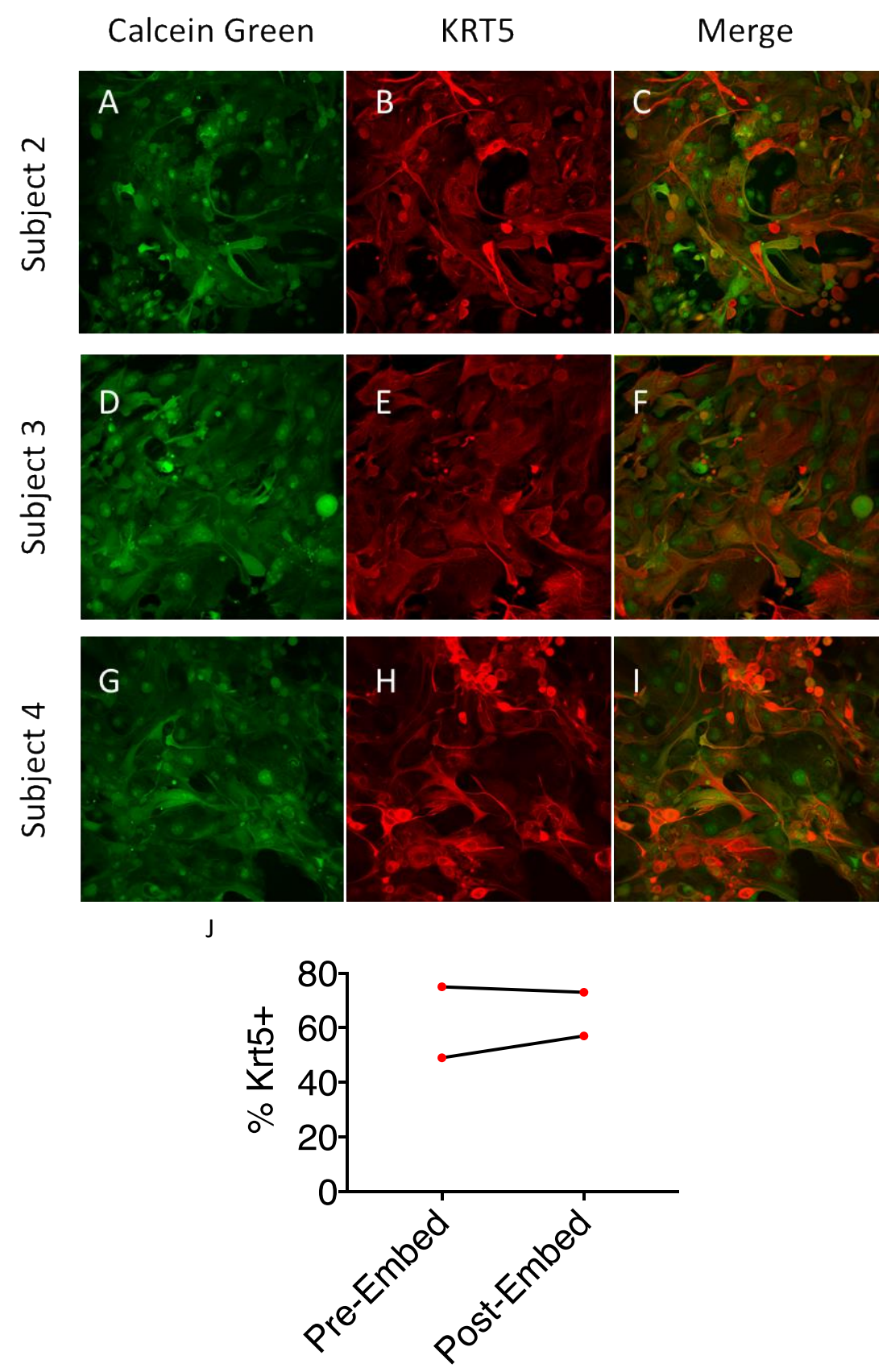

Figure S5: (A-I) Sheets fixed on day 4 after embedding on pSIS membrane were KRT5+. Calcein green indicates live cells and KRT5+ cells are stained red. Images from 3 additional subjects are shown here. (J) The fraction of KRT5+ cells was measured by flow cytometry on the day of embedding in pSIS membranes (Pre-embed). The fraction of calcein green positive cells that were also KRT5+ on day 4 after embedding was determined using confocal microscopy (Post-embed). The fraction of KRT5+ cells were similar indicating that edited cells did not experience a proliferative disadvantage. Thus, the pSIS membrane is a suitable scaffold to optimize transplantation of corrected cells in animal models. 


\section{Figure S6}

A

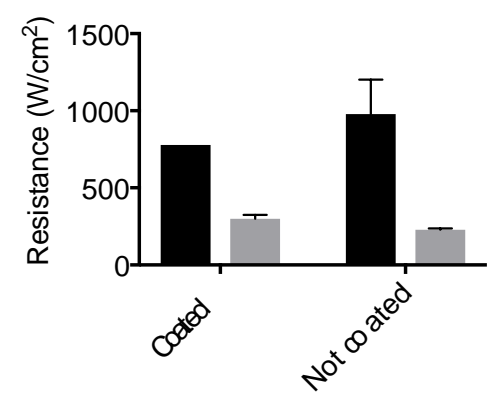

C

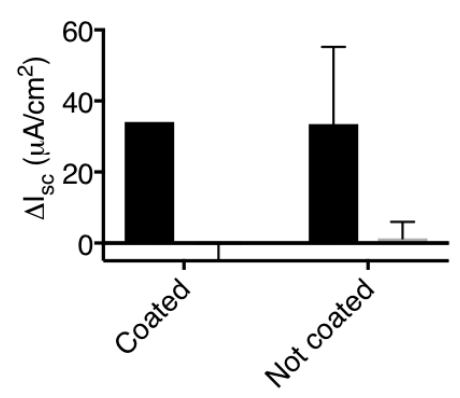

B

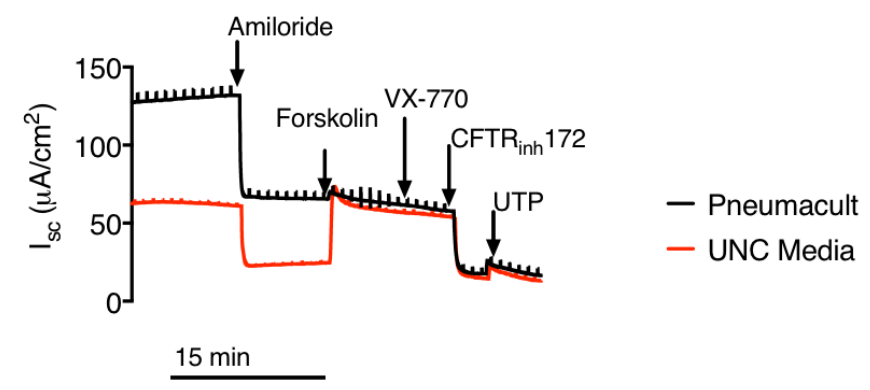

D

CFTR $_{\text {inh }}-172$

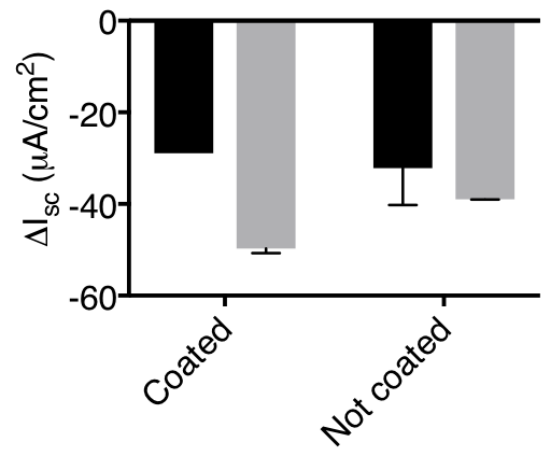

UNC

Pneumacult

$\mathrm{E}$

UNC

Pneumacult

$\Delta \mathrm{F} / \Delta \mathrm{F} C F$ Sample in Pneumacult media

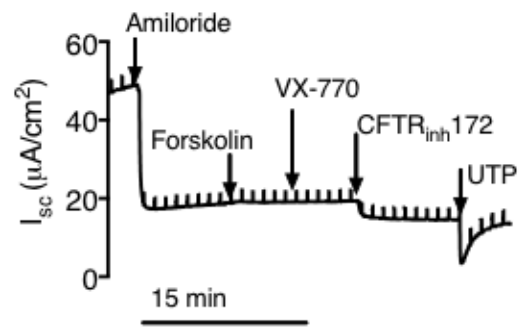

$\Delta \mathrm{F} / \Delta \mathrm{F}$ CF Sample in UNC media
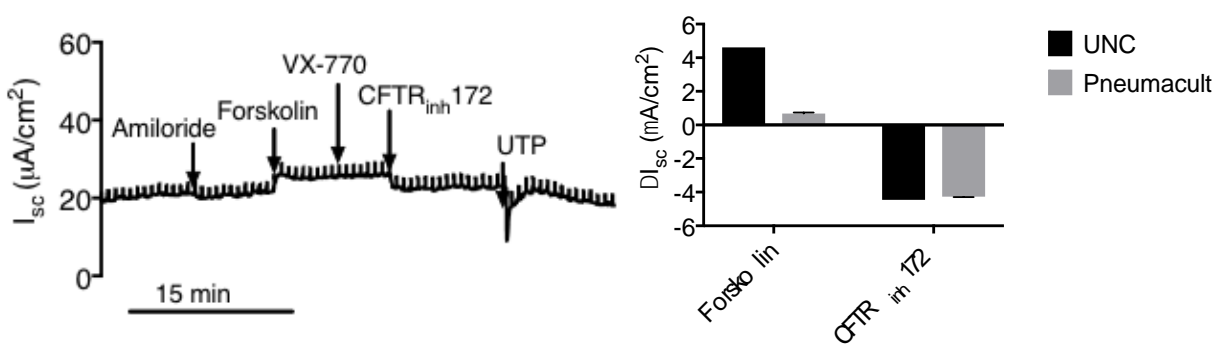

Figure S6: (A) UABCs from non-CF patients cultured in UNC media showed higher transepithelial resistances after differentiation on ALI (B) Representative traces from epithelial monolayers cultured in Pneumacult ${ }^{T M}$ ALI and UNC media. Monolayers cultured in UNC media showed a more pronounced forskolin response. (C) In non-CF samples, short-circuit currents in response to forskolin were higher in monolayers cultured in UNC media. The presence or absence of collagen IV coating did not affect forskolin responses (D) Responses to CFTRinh-172 were similar between monolayers cultured in UNC media and Pneumacult ALI ${ }^{\mathrm{TM}}$ for non-CF cells. The presence or absence of collagen IV coating did not affect CFTRinh-172 responses (E) Upper airway basal cells from $\Delta \mathrm{F} 508$ homozygous patient were edited (27\% allelic correction) and differentiated using Pneumacult ALI ${ }^{\mathrm{TM}}$ and UNC media (no collagen IV coating) on ALI membranes. Similar 
bioRxiv preprint doi: https://doi.org/10.1101/561183; this version posted February 26, 2019. The copyright holder for this preprint (which was not certified by peer review) is the author/funder, who has granted bioRxiv a license to display the preprint in perpetuity. It is made available under aCC-BY-NC-ND 4.0 International license.

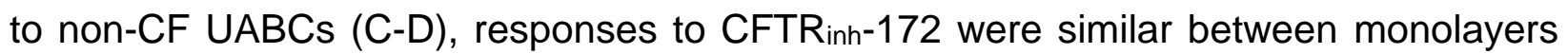
cultured in UNC media and Pneumacult ${ }^{\mathrm{TM}}$ ALI but monolayers cultured in UNC media showed higher forskolin-stimulated short-circuit currents. 
Table S1: Off-target Activity of MS-SgRNA. Cas9 can induce double stranded breaks even if there are a few mismatches between the target genomic DNA and sgRNA. As a result, undesired insertions and deletions at off-target (OT) sites can happen. The MSsgRNA targeting the $\triangle \mathrm{F} 508$ locus shows very low levels of OT activity $(<0.2 \%)$ at one locus (OT-41) and high levels of on target activity. Mismatches are highlighted in bold and the protospacer adjacent motif (PAM) is underlined.

\begin{tabular}{|c|c|c|c|c|c|c|}
\hline & Protospacer - PAM & Mock & $\begin{array}{c}\text { Edited } \\
\text { Subject } 1\end{array}$ & $\begin{array}{c}\text { Edited } \\
\text { Subject } 1\end{array}$ & $\begin{array}{c}\text { Edited } \\
\text { Subject } 2\end{array}$ & Gene \\
\hline $\begin{array}{l}\text { On } \\
\text { target }\end{array}$ & TCTGTATCTATATTCATCATAGG & 0.00 & 73.63 & 80.87 & 77.12 & CFTR \\
\hline OT1 & TTTATGTCTATATTCATCATGGG & 0.01 & 0.00 & 0.00 & 0.00 & SLC4A10 \\
\hline OT2 & CATTTATTTATATTCATCATGGG & 0.00 & 0.00 & 0.00 & 0.00 & TTTY5 \\
\hline OT3 & CATTTATTTATATTCATCATGGG & 0.00 & 0.00 & 0.00 & 0.02 & TTTY12 \\
\hline OT4 & ACTTGATTTATATTCATCATAGG & 0.00 & 0.00 & 0.00 & 0.00 & MBL2 \\
\hline OT5 & ACAGTATAAATATTCATCATAGG & 0.00 & 0.00 & 0.00 & 0.00 & PPIA \\
\hline OT6 & CCTTTATACATATTCATCATTGG & 0.00 & 0.00 & 0.01 & 0.01 & NLRP2B \\
\hline OT7 & ATTGTTTCTCTATTCATCATTGG & 0.01 & 0.01 & 0.00 & 0.00 & FAM169A \\
\hline OT8 & ACTGTAAACATATTCATCATAGG & 0.00 & 0.00 & 0.00 & 0 & PHF21B \\
\hline OT9 & GCTGCATCATTATTCATCATCGG & 0.01 & 0.00 & 0.01 & 0.00 & OR6K6 \\
\hline OT10 & TTTGCATCTATGTTCATCATAGG & 0.01 & 0.00 & 0.01 & 0.01 & UBA6-AS1 \\
\hline OT11 & TTTGCATCTATGTTCATCATGGG & 0.00 & 0.00 & 0.00 & 0 & RGMB \\
\hline OT12 & TTTGTGTCTATGTTCATCATAGG & 0.00 & 0.00 & 0.01 & 0.00 & MOCOS \\
\hline OT13 & TTTGTGTCTATGTTCATCATGGG & 0.00 & 0.00 & 0.00 & 0.00 & RANBP17 \\
\hline OT14 & ACTGTGTCCAGATTCATCATAGG & 0.00 & 0.00 & 0.00 & 0.00 & COL11A1 \\
\hline OT15 & ACTGTAGCAAAATTCATCATTGG & 0.00 & 0.00 & 0.00 & 0.00 & VIM-AS1 \\
\hline OT16 & TCTATATCTTCATTCATCATGGG & 0.00 & 0.01 & 0.09 & 0.00 & LRRTM4 \\
\hline OT17 & CСTATCTCTATAATCATCATGGG & 0.00 & 0.01 & 0.01 & 0.00 & MTHFS \\
\hline OT18 & TCTGCATCTATATACATCATCAG & 0.00 & 0.01 & 0.01 & 0.00 & MSS51 \\
\hline OT19 & TCTTTCTCTATATCCATCATAGG & 0.01 & 0.00 & 0.00 & 0.01 & MIR4451 \\
\hline OT20 & TCTGTTTATATATCCATCATGGG & 0.01 & 0.01 & 0.01 & 0.00 & NCAM2 \\
\hline OT21 & ACTGTAACTATTCTCATCATAGG & 0.00 & 0.00 & 0.00 & 0.00 & RNF141 \\
\hline OT22 & GGTCTATCTATATTTATCATTGG & 0.01 & 0.01 & 0.01 & 0.02 & NRG1 \\
\hline OT23 & ACTGTATCAATATTGATCATTAG & 0.02 & 0.03 & 0.01 & 0.01 & MIR488 \\
\hline OT24 & CCTATATCTATCTACATCATAGG & 0.01 & 0.00 & 0.00 & 0 & XIRP2 \\
\hline OT25 & TCTATATTTATATTAATCATAGG & 0.02 & 0.02 & 0.01 & 0 & LINC01243 \\
\hline OT26 & CCTGTGTCTATGTTTATCATAGG & 0.01 & 0.00 & 0.00 & 0.03 & LOC105374194 \\
\hline OT27 & CCTTTATCTATATTCACCATGGG & 0.00 & 0.01 & 0.00 & 0.00 & CALM2 \\
\hline OT28 & ACTGCATCTATGTTCTTCATGGG & 0.00 & 0.00 & 0.01 & 0.00 & OTOR \\
\hline OT29 & CCTATATCCATATTCACCATTGG & 0.02 & 0.02 & 0.01 & 0.01 & NRP2 \\
\hline OT30 & TCTGTGTCTATAATCTTCATAGG & 0.00 & 0.02 & 0.02 & 0.01 & MGAT4C \\
\hline OT31 & GCTATATCTATATCCTTCATTGG & 0.02 & 0.04 & 0.01 & 0.00 & LOC101927394 \\
\hline
\end{tabular}




\begin{tabular}{|l|c|c|c|c|c|c|}
\hline OT32 & CCTGTATATATATTCATAATIAG & 0.01 & 0.02 & 0.01 & 0.02 & LOC100422212 \\
\hline OT33 & TCTGTATGTATATTCATGATGAG & 0.00 & 0.00 & 0.01 & 0.00 & PSD3 \\
\hline OT34 & TCTATATCTATAGTCAGCATIGG & 0.00 & 0.00 & 0.00 & 0.00 & MRGPRX3 \\
\hline OT35 & CCTGTATCTATTTTCATAATGAG & 0.018 & 0.022 & 0.06 & 0.016 & MACROD2 \\
\hline OT36 & CCTGTATCTATATTAAACATAGG & 0.02 & 0.01 & 0.00 & 0.01 & MIR5011 \\
\hline OT37 & TCTGTATCTATATTCATCA-GGG & 0.00 & 0.01 & 0.01 & 0.01 & CNTNAP5 \\
\hline OT38 & TCTGTATCTATGTTCATCACAGG & 0.00 & 0.01 & 0.01 & 0.00 & LINC00331 \\
\hline OT39 & ACTGTATCTATATTCATAAGGGG & 0.02 & 0.02 & 0.01 & 0.03 & LOC101928437 \\
\hline OT40 & TTTGTGTCTATATTCATAATAGG & 0.02 & 0.01 & 0.01 & 0.00 & LOC102723895 \\
\hline OT41 & TCTATATCTATATACACCATAGG & 0.01 & 0.18 & 0.15 & 0.224 & DIXDC1 \\
\hline OT42 & GCTGTATTTATATCCAACATGGG & 0.00 & 0.00 & 0.00 & 0 & LINC00618 \\
\hline OT43 & GCTGTATCTTTACTCACCATIGG & 0 & 0 & 0 & 0 & VCX3B \\
\hline OT44 & TCTGCATGTATATTCATCAGTGG & 0.00 & 0.00 & 0.01 & 0.01 & MRGPRX3 \\
\hline OT45 & GCTGAATCTATATTGATCCTGGG & 0.01 & 0.00 & 0.00 & 0.00 & DNAH6 \\
\hline OT46 & ACTGTTTCTATATTTATCGTAGG & 0.03 & 0.01 & 0.00 & 0.07 & GARNL3 \\
\hline OT47 & TCTGTATTTATATTTATCCTGGG & 0.01 & 0.01 & 0.01 & 0.01 & ATP6V0D2 \\
\hline
\end{tabular}




\section{References:}

Armstrong, D.K., Cunningham, S., Davies, J.C., and Alton, E.W.F.W. (2014). Gene therapy in cystic fibrosis. Arch. Dis. Child. 99, 465 LP-468.

Bak, R.O., Dever, D.P., and Porteus, M.H. (2018). CRISPR/Cas9 genome editing in human hematopoietic stem cells. Nat. Protoc. 13, 358-376.

Bravo, D.T., Soudry, E., Edward, J.A., Le, W., Nguyen, A.L., Hwang, P.H., Sanyal, M., and Nayak, J. V. (2013). Characterization of human upper airway epithelial progenitors. Int. Forum Allergy Rhinol. 3, 841-847.

Brinkman, E.K., Kousholt, A.N., Harmsen, T., Leemans, C., Chen, T., Jonkers, J., and van Steensel, B. (2018). Easy quantification of template-directed CRISPR/Cas9 editing. Nucleic Acids Res. 46, e58.

Char, J.E., Wolfe, M.H., Cho, H.J., Park, I.H., Jeong, J.H., Frisbee, E., Dunn, C., Davies, Z., Milla, C., Moss, R.B., et al. (2014). A little CFTR goes a long way: CFTRdependent sweat secretion from G551D and R117H-5T cystic fibrosis subjects taking ivacaftor. PLoS One 9, 1-16.

Charlesworth, C.T., Camarena, J., Cromer, M.K., Vaidyanathan, S., Bak, R.O., Carte, J.M., Potter, J., Dever, D.P., and Porteus, M.H. (2018). Priming Human Repopulating Hematopoietic Stem and Progenitor Cells for Cas9/sgRNA Gene Targeting. Mol. Ther. Nucleic Acids 12, 89-104.

Charlesworth, C.T., Deshpande, P.S., Dever, D.P., Camarena, J., Lemgart, V.T., Cromer, M.K., Vakulskas, C.A., Collingwood, M.A., Zhang, L., Bode, N.M., et al. (2019). Identification of preexisting adaptive immunity to Cas9 proteins in humans. Nat. Med.

Cooney, A.L., Abou Alaiwa, M.H., Shah, V.S., Bouzek, D.C., Stroik, M.R., Powers, L.S., Gansemer, N.D., Meyerholz, D.K., Welsh, M.J., Stoltz, D.A., et al. (2016). Lentiviralmediated phenotypic correction of cystic fibrosis pigs. JCl Insight 1, e88730.

Cradick, T.J., Qiu, P., Lee, C.M., Fine, E.J., and Bao, G. (2014). COSMID: A web-based tool for identifying and validating CRISPR/Cas off-target sites. Mol. Ther. - Nucleic Acids 3, e214.

Crane, A.M., Kramer, P., Bui, J.H., Chung, W.J., Li, X.S., Gonzalez-Garay, M.L., Hawkins, F., Liao, W., Mora, D., Choi, S., et al. (2015). Targeted correction and restored function of the CFTR gene in cystic fibrosis induced pluripotent stem cells. Stem Cell Reports 4, 569-577.

Dever, D.P., Bak, R.O., Reinisch, A., Camarena, J., Washington, G., Nicolas, C.E., Pavel-Dinu, M., Saxena, N., Wilkens, A.B., Mantri, S., et al. (2016). CRISPR/Cas9 $\beta$ globin gene targeting in human haematopoietic stem cells. Nature 539, 384-389.

Firth, A.L., Menon, T., Parker, G.S., Qualls, S.J., Lewis, B.M., Ke, E., Dargitz, C.T., Wright, R., Khanna, A., Gage, F.H., et al. (2015). Functional Gene Correction for Cystic Fibrosis in Lung Epithelial Cells Generated from Patient iPSCs. Cell Rep. 12, 13851390.

Fujii, M., Matano, M., Nanki, K., and Sato, T. (2015). Efficient genetic engineering of 
human intestinal organoids using electroporation. Nat. Protoc. 10, 1474-1485.

Gentzsch, M., Boyles, S.E., Cheluvaraju, C., Chaudhry, I.G., Quinney, N.L., Cho, C., Dang, H., Liu, X., Schlegel, R., and Randell, S.H. (2017). Pharmacological rescue of conditionally reprogrammed cystic fibrosis bronchial epithelial cells. Am. J. Respir. Cell Mol. Biol. 56, 568-574.

Van Goor, F., Hadida, S., Grootenhuis, P.D.J., Burton, B., Cao, D., Neuberger, T., Turnbull, A., Singh, A., Joubran, J., Hazlewood, A., et al. (2009). Rescue of CF airway epithelial cell function in vitro by a CFTR potentiator, VX-770. Proc. Natl. Acad. Sci. 106, 18825-18830.

Van Goor, F., Hadida, S., Grootenhuis, P.D.J., Burton, B., Stack, J.H., Straley, K.S., Decker, C.J., Miller, M., McCartney, J., Olson, E.R., et al. (2011). Correction of the F508del-CFTR protein processing defect in vitro by the investigational drug VX-809. Proc. Natl. Acad. Sci. 108, 18843-18848.

Griesenbach, U., Pytel, K.M., and Alton, E.W.F.W. (2015). Cystic Fibrosis Gene Therapy in the UK and Elsewhere. Hum. Gene Ther. 26, 266-275.

Hansen, S.K., Rau, M.H., Johansen, H.K., Ciofu, O., Jelsbak, L., Yang, L., Folkesson, A., Jarmer, H.Ø., Aanæs, K., von Buchwald, C., et al. (2012). Evolution and diversification of Pseudomonas aeruginosa in the paranasal sinuses of cystic fibrosis children have implications for chronic lung infection. ISME J. 6, 31-45.

Hendel, A., Kildebeck, E.J., Fine, E.J., Clark, J.T., Punjya, N., Sebastiano, V., Bao, G., and Porteus, M.H. (2014). Quantifying Genome-Editing Outcomes at Endogenous Loci with SMRT Sequencing. Cell Rep. 7, 293-305.

Hendel, A., Bak, R.O., Clark, J.T., Kennedy, A.B., Ryan, D.E., Roy, S., Steinfeld, I., Lunstad, B.D., Kaiser, R.J., Wilkens, A.B., et al. (2015). Chemically modified guide RNAs enhance CRISPR-Cas genome editing in human primary cells. Nat. Biotechnol. 33, 985-989.

Hsu, P.D., Scott, D.A., Weinstein, J.A., Ran, F.A., Konermann, S., Agarwala, V., Li, Y., Fine, E.J., Wu, X., Shalem, O., et al. (2013). DNA targeting specificity of RNA-guided Cas9 nucleases. Nat. Biotechnol. 31, 827.

Johnson, L.G., Olsen, J.C., Sarkadi, B., Moore, K.L., Swanstrom, R., and Boucher, R.C. (1992). Efficiency of gene transfer for restoration of normal airway epithelial function in cystic fibrosis. Nat. Genet. 2, 21-25.

Lee, C.M., Cradick, T.J., and Bao, G. (2016). The Neisseria meningitidis CRISPR-Cas9 System Enables Specific Genome Editing in Mammalian Cells. Mol. Ther. 24, 645-654.

Lin, Y., Cradick, T.J., Brown, M.T., Deshmukh, H., Ranjan, P., Sarode, N., Wile, B.M., Vertino, P.M., Stewart, F.J., and Bao, G. (2014). CRISPR/Cas9 systems have off-target activity with insertions or deletions between target DNA and guide RNA sequences. Nucleic Acids Res. 42, 7473-7485.

Ma, T., Thiagarajah, J.R., Yang, H., Sonawane, N.D., Folli, C., Galietta, L.J. V, and Verkman, A.S. (2002). Thiazolidinone CFTR inhibitor identified by high-throughput screening blocks cholera toxin-induced intestinal fluid secretion. J. Clin. Invest. 110, 
$1651-1658$.

Martin, R., Ikeda, K., Uchida, N., Cromer, M.K., Nishimura, T., Dever, D.P., Camarena, J., Bak, R., Lausten, A., Jakobsen, M.R., et al. (2018). Selection-free, high frequency genome editing by homologous recombination of human pluripotent stem cells using Cas9 RNP and AAV6. BioRxiv 252163.

McKone, E.F., Emerson, S.S., Edwards, K.L., and Aitken, M.L. (2003). Effect of genotype on phenotype and mortality in cystic fibrosis: a retrospective cohort study. Lancet 361, 1671-1676.

Nayak, J. V., Rathor, A., Grayson, J.W., Bravo, D.T., Velasquez, N., Noel, J., Beswick, D.M., Riley, K.O., Patel, Z.M., Cho, D.-Y., et al. (2018). Porcine small intestine submucosal grafts improve remucosalization and progenitor cell recruitment to sites of upper airway tissue remodeling. Int. Forum Allergy Rhinol. 00, 1-7.

De Nooijer, R.A., Nobel, J.M., Arets, H.G.M., Bot, A.G., van Berkhout, F.T., de Rijke, Y.B., de Jonge, H.R., and Bronsveld, I. (2011). Assessment of CFTR function in homozygous R117H-7T subjects. J. Cyst. Fibros. 10, 326-332.

Oliveria, R.A.F. de, Pedrazini, M.C., and Wassall, T. (2014). Relative area measurement of maxillary sinus by computed tomography. RGO - Rev. Gaúcha Odontol. 62, 111-116.

Rosen, C., Shezen, E., Aronovich, A., Klionsky, Y.Z., Yaakov, Y., Assayag, M., Biton, I.E., Tal, O., Shakhar, G., Ben-Hur, H., et al. (2015). Preconditioning allows engraftment of mouse and human embryonic lung cells, enabling lung repair in mice. Nat. Med. 21, 869.

Schwank, G., Koo, B.K., Sasselli, V., Dekkers, J.F., Heo, I., Demircan, T., Sasaki, N., Boymans, S., Cuppen, E., Van Der Ent, C.K., et al. (2013). Functional repair of CFTR by CRISPR/Cas9 in intestinal stem cell organoids of cystic fibrosis patients. Cell Stem Cell 13, 653-658.

Shah, V.S., Ernst, S., Tang, X.X., Karp, P.H., Parker, C.P., Ostedgaard, L.S., and Welsh, M.J. (2016). Relationships among CFTR expression, $\mathrm{HCO}_{3}{ }^{-}$secretion, and host defense may inform gene- and cell-based cystic fibrosis therapies. Proc. Natl. Acad. Sci. 113, 5382-5387.

Sheppard, D.N., Rich, D.P., Ostedgaard, L.S., Gregory, R.J., Smith, A.E., and Welsh, M.J. (1993). Mutations in CFTR associated with mild-disease-form Cl-channels with altered pore properties. Nature 362, 160-164.

Vu, C.B., Bridges, R.J., Pena-Rasgado, C., Lacerda, A.E., Bordwell, C., Sewell, A., Nichols, A.J., Chandran, S., Lonkar, P., Picarella, D., et al. (2017). Fatty Acid Cysteamine Conjugates as Novel and Potent Autophagy Activators That Enhance the Correction of Misfolded F508del-Cystic Fibrosis Transmembrane Conductance Regulator (CFTR). J. Med. Chem. 60, 458-473.

Wagner, D.L., Amini, L., Wendering, D.J., Burkhardt, L.-M., Akyüz, L., Reinke, P., Volk, H.-D., and Schmueck-Henneresse, M. (2018). High prevalence of Streptococcus pyogenes Cas9-reactive T cells within the adult human population. Nat. Med. 
Wagner, J.A., Nepomuceno, I.B., Messner, A.H., Moran, M.L., Batson, E.P., Dimiceli, S., Brown, B.W., Desch, J.K., Norbash, A.M., Conrad, C.K., et al. (2002). A Phase II, Double-Blind, Randomized, Placebo-Controlled Clinical Trial of tgAAVCF Using Maxillary Sinus Delivery in Patients with Cystic Fibrosis with Antrostomies. Hum. Gene Ther. 13, 1349-1359.

Wainwright, C.E., Elborn, J.S., Ramsey, B.W., Marigowda, G., Huang, X., Cipolli, M., Colombo, C., Davies, J.C., De Boeck, K., Flume, P.A., et al. (2015). LumacaftorIvacaftor in Patients with Cystic Fibrosis Homozygous for Phe508del CFTR. N. Engl. J. Med. 373, 220-231.

Wang, D., Mou, H., Li, S., Li, Y., Hough, S., Tran, K., Li, J., Yin, H., Anderson, D.G., Sontheimer, E.J., et al. (2015a). Adenovirus-Mediated Somatic Genome Editing of Pten by CRISPR/Cas9 in Mouse Liver in Spite of Cas9-Specific Immune Responses. Hum. Gene Ther. 26, 432-442.

Wang, D.Y., Li, Y., Yan, Y., Li, C., and Shi, L. (2015b). Upper Airway Stem Cells: Understanding the Nose and Role for Future Cell Therapy. Curr. Allergy Asthma Rep. 15, 1-9.

Wang, X., Zheng, L., Zeng, Z., Zhou, G., Chien, J., Qian, C., Vasmatzis, G., Shridhar, V., Chen, L., and Liu, W. (2006). DIXDC1 isoform, I-DIXDC1, is a novel filamentous actin-binding protein. Biochem. Biophys. Res. Commun. 347, 22-30. 